\title{
Stereoselective Synthesis of the ABC Ring System of Norzoanthamine
}

Subhash Ghosh, Fatima Rivas, Derek Fischer, Miguel A. González, and Emmanuel A. Theodorakis*

Department of Chemistry and Biochemistry, University of California, San Diego, 9500 Gilman Drive, La Jolla, CA 92093-0358

*etheodor@chem.ucsd.edu

\section{Supporting Information}

Table of Contents

1. General Techniques

2

2. Experimental Procedures

3-8

3. NMR Spectra

9-34 


\section{General Techniques}

All reagents were commercially obtained (Aldrich, Acros) at highest commercial quality and used without further purification except where noted. Air- and moisture-sensitive liquids and solutions were transferred via syringe or stainless steel cannula. Organic solutions were concentrated by rotary evaporation below $45{ }^{\circ} \mathrm{C}$ at approximately 20 $\mathrm{mmHg}$. All non-aqueous reactions were carried out under anhydrous conditions using flame-dried glassware within an argon atmosphere in dry, freshly distilled solvents, unless otherwise noted. Tetrahydrofuran (THF), diethyl ether $\left(\mathrm{Et}_{2} \mathrm{O}\right)$, dichloromethane $\left(\mathrm{CH}_{2} \mathrm{Cl}_{2}\right)$, toluene $\left(\mathrm{PhCH}_{3}\right)$ and benzene $(\mathrm{PhH})$ were purified by passage through a bed of activated alumina. ${ }^{1} \quad N, N$-diisopropylethylamine (DIPEA), diisopropylamine, pyridine, triethylamine (TEA) and boron trifluoride etherate were distilled from calcium hydride prior to use. ${ }^{2}$ Dimethyl sulfoxide (DMSO) and dimethylformamide (DMF) were distilled from calcium hydride under reduced pressure $(20 \mathrm{mmHg})$ and stored over $4 \AA$ molecular sieves until needed. Yields refer to chromatographically and spectroscopically $\left({ }^{1} \mathrm{H}\right.$ NMR, ${ }^{13} \mathrm{C}$ NMR) homogeneous materials, unless otherwise stated. Reactions were monitored by thin-layer chromatography (TLC) carried out on $0.25 \mathrm{~mm}$ E. Merck silica gel plates (60F-254) using UV light as the visualizing agent and 10\% ethanolic phosphomolybdic acid (PMA) or $p$-anisaldehyde solution and heat as developing agents. E. Merck silica gel (60, particle size $0.040-0.063 \mathrm{~mm}$ ) was used for flash chromatography. Preparative thin-layer chromatography separations were carried out on 0.25 or $0.50 \mathrm{~mm}$ E. Merck silica gel plates (60F-254). NMR spectra were recorded on Varian Mercury 300, 400 and/or Unity $500 \mathrm{MHz}$ instruments and calibrated using the residual undeuterated solvent as an internal reference. The following abbreviations were used to explain the multiplicities: $\mathrm{s}=$ singlet, $\mathrm{d}=$ doublet, $\mathrm{t}=$ triplet, $\mathrm{q}=$ quartet, $\mathrm{m}=$ multiplet, $\mathrm{b}=$ broad. IR spectra were recorded on a Nicolet 320 Avatar FT-IR spectrometer and values are reported in $\mathrm{cm}^{-1}$ units. Optical rotations were recorded on a Jasco P-1010 polarimeter and values are reported as follows: $[\alpha]^{\mathrm{T}} \lambda(\mathrm{c}: \mathrm{g} / 100 \mathrm{ml}$, solvent). High resolution mass spectra (HRMS) were recorded on a VG 7070 HS mass spectrometer under chemical

\footnotetext{
1 . Pangborn, A. B.; Giardello, M. A.; Grubbs, R. H.; Rosen, R. K.; Timmers, F. J. Organometallics 1996, 15, 1518-1520.

2. Perrin, D. D.; Armarego, W. L. Purification of Laboratory Chemicals, 3rd ed.; Pergamon Press: Oxford, 1988.
} 
ionization $(\mathrm{CI})$ conditions or on a VG ZAB-ZSE mass spectrometer under fast atom bombardment (FAB) conditions. X-ray data were recorded on a Bruker SMART APEX 3kW Sealed Tube X-ray diffraction system.

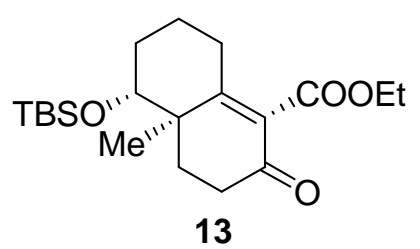

Ester 13: To a stirred solution of enone 8 (11.2 $\mathrm{g}, 44.7 \mathrm{mmol})$ in dry $\mathrm{EtOH}(180 \mathrm{~mL})$ at $-78{ }^{\circ} \mathrm{C}$ was added $\mathrm{NaBH}_{4}(413 \mathrm{mg}$, $11.1 \mathrm{mmol})$ portionwise $(4 \mathrm{x} 100 \mathrm{mg})$ The reaction mixture was stirred at that temperature for $1 \mathrm{~h}$ and was quenched with glacial acetic acid $(2 \mathrm{~mL})$. After evaporation of $\mathrm{EtOH}$ under reduced pressure, the residue was extracted with ethyl acetate $(3 \times 100$ $\mathrm{mL})$. The combined organic extracts were washed with brine $(2 \times 100 \mathrm{~mL})$, dried over $\mathrm{MgSO}_{4}$, concentrated under reduced pressure and purified by flash chromatography (silica, 40:60 ethyl acetate in hexanes) to give the corresponding C13 alcohol (10.39 g, $41.1 \mathrm{mmol} 92 \%$ ), as a white solid $\mathrm{R}_{\mathrm{f}}=0.25$ (50\% ethyl acetate in hexanes); ${ }^{1} \mathrm{H}$ NMR $\left(400 \mathrm{MHz}, \mathrm{CDCl}_{3}\right) \delta 4.24(2 \mathrm{H}, \mathrm{q}, J=7.0 \mathrm{~Hz}), 3.45(1 \mathrm{H}, \mathrm{m}), 2.51-2.00(6 \mathrm{H}, \mathrm{m}), 1.91-1.78$ $(3 \mathrm{H}, \mathrm{m}), 1.72(1 \mathrm{H}, \mathrm{m}), 1.41(1 \mathrm{H}, \mathrm{m}), 1.90(3 \mathrm{H}, \mathrm{t}, J=7.0 \mathrm{~Hz}), 1.20(3 \mathrm{H}, \mathrm{s}) ;{ }^{13} \mathrm{C} \mathrm{NMR}$ $\left(100 \mathrm{MHz}, \mathrm{CDCl}_{3}\right) \delta 195.0,166.9,164.7,131.9,77.5,61.3,41.5,33.3,33.2,29.8,29.0$, 22.7, 15.6, 14.2.

A solution of alcohol obtained in the above step (10.0 g, $39.63 \mathrm{mmol})$ and dry DMF (70 $\mathrm{mL})$ was treated with ammonium nitrate $(9.5 \mathrm{~g}, 118.9 \mathrm{mmol})$ and $\mathrm{TBSCl}(8.9 \mathrm{~g}, 59.4$ mmol) at $0{ }^{\circ} \mathrm{C}$. The mixture was warmed to $25{ }^{0}{ }^{\circ} \mathrm{C}$ and stirred overnight, and then quenched with a saturated solution of aqueous ammonium chloride $(30 \mathrm{~mL})$. The reaction mixture was extracted with ethyl acetate $(2 \times 150 \mathrm{~mL})$. The combined organic extracts were washed with brine $(2 \times 100 \mathrm{~mL})$, dried over $\mathrm{MgSO}_{4}$, concentrated under reduced pressure and purified by flash chromatography (silica, 6:94 ethyl acetate in hexanes), to give 13 (13.07 g, $35.65 \mathrm{mmol}, 90 \%)$. 13: White solid: $\mathrm{R}_{\mathrm{f}}=0.47$ (20\% ethyl acetate in hexanes); ${ }^{1} \mathrm{H}$ NMR $\left(400 \mathrm{MHz}, \mathrm{CDCl}_{3}\right) \delta 4.27(2 \mathrm{H}, \mathrm{q}, J=7.2 \mathrm{~Hz}), 3.44(1 \mathrm{H}, \mathrm{dd}, J=4.8$, $11.2 \mathrm{~Hz}), 2.50-2.40(2 \mathrm{H}, \mathrm{m}), 2.35-2.10(2 \mathrm{H}, \mathrm{m}), 2.10(1 \mathrm{H}, \mathrm{m}), 1.86(1 \mathrm{H}, \mathrm{m}), 1.80-1.66$ $(3 \mathrm{H}, \mathrm{m}), 1.42(1 \mathrm{H}, \mathrm{m}), 1.31(3 \mathrm{H}, \mathrm{t}, J=7.2 \mathrm{~Hz}), 1.21(3 \mathrm{H}, \mathrm{s}), 0.90(9 \mathrm{H}, \mathrm{s}), 0.06(3 \mathrm{H}, \mathrm{s})$, $0.045(3 \mathrm{H}, \mathrm{s}) ;{ }^{13} \mathrm{C} \mathrm{NMR}\left(100 \mathrm{MHz}, \mathrm{CDCl}_{3}\right) \delta 194.4,166.5,164.0,131.7,78.1,60.8$, 41.7, 33.5, 33.2, 30.1, 28.7, 25.6, 25.5, 22.3, 17.8, 15.6, 14.0, -4.1, -5.0; HRMS calcd. for $\mathrm{C}_{20} \mathrm{H}_{34} \mathrm{O}_{4} \mathrm{Si}\left(\mathrm{M}+\mathrm{Na}^{+}\right)$389.2124, found 389.2103.

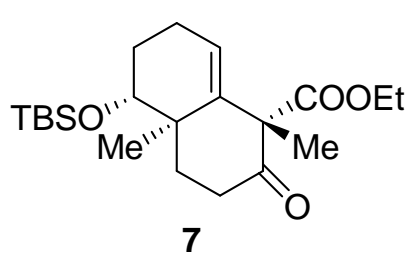

Ester 7: A solution of compound 13 (10.0 g, $27.28 \mathrm{mmol})$ was added to a suspension of potassium tert-butoxide (3.36 g, 30 mmol $)$ in dry benzene $(100 \mathrm{~mL})$ at $0{ }^{\circ} \mathrm{C}$. After stirring at $25{ }^{\circ} \mathrm{C}$ for $30 \mathrm{~min}$ it was cooled to $0{ }^{\circ} \mathrm{C}$ and treated with excess methyl iodide $(5 \mathrm{~mL}, 80.31 \mathrm{mmol})$. After stirring for $12 \mathrm{~h}$ at $25{ }^{\circ} \mathrm{C}$ the reaction mixture was quenched with saturated solution of aqueous ammonium chloride $(30 \mathrm{~mL})$ and extracted with ethyl acetate $(2 \times 100 \mathrm{~mL})$. The combined organic extracts were washed with brine $(100 \mathrm{~mL})$, dried over $\mathrm{MgSO}_{4}$, concentrated under reduced pressure and purified by flash chromatography (silica, 4:96 
ethyl acetate in hexanes) to give $7(7.05 \mathrm{~g}, 18.7 \mathrm{mmol}, 68 \%)$. 7: White solid: $\mathrm{R}_{\mathrm{f}}=0.5$ (20\% ethyl acetate in hexanes); ${ }^{1} \mathrm{H}$ NMR $\left(400 \mathrm{MHz}, \mathrm{CDCl}_{3}\right) \delta 5.52(1 \mathrm{H}, \mathrm{t}, J=3.8 \mathrm{~Hz})$, 4.20-4.06 (2H, m), $3.47(1 \mathrm{H}, \mathrm{dd}, J=11.6,3.6, \mathrm{~Hz}), 2.70(1 \mathrm{H}, \mathrm{m}), 2.42(1 \mathrm{H}, \mathrm{m}), 2.20-2.04$ $(3 \mathrm{H}, \mathrm{m}), 1.78(1 \mathrm{H}, \mathrm{m}), 1.73-1.63(3 \mathrm{H}, \mathrm{m}), 1.43(3 \mathrm{H}, \mathrm{s}), 1.22(3 \mathrm{H} \mathrm{t}, J=6.8 \mathrm{~Hz}), 1.08(3 \mathrm{H}$, s), $0.90(9 \mathrm{H}, \mathrm{s}), 0.07(3 \mathrm{H}, \mathrm{s}), 0.04(3 \mathrm{H}, \mathrm{s}) ;{ }^{13} \mathrm{C} \mathrm{NMR}\left(100 \mathrm{MHz}, \mathrm{CDCl}_{3}\right) \delta 208.4,172.6$, 141.8, 123.6, 76.0, 61.4, 60.3, 39.9, 34.9, 32.7, 26.6, 25.9, 24.8, 22.7,18.3, 18.1, 14.0, 3.8, -4.7; HRMS calcd. for $\mathrm{C}_{21} \mathrm{H}_{36} \mathrm{O}_{4} \mathrm{Si}\left(\mathrm{M}+\mathrm{Na}^{+}\right)$403.2281, found 403.2270.

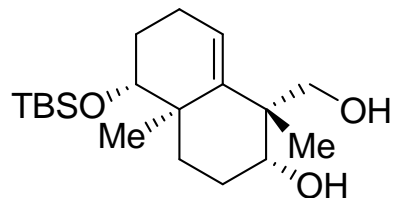

Alkene 14 Precursor: Lithium aluminum hydride (1.36 g, 36.8 mmol) was added to a stirred solution of compound 7 ( $7.0 \mathrm{~g}$, $18.4 \mathrm{mmol})$ in dry tetrahydrofuran $(100 \mathrm{~mL})$ at $0{ }^{\circ} \mathrm{C}$. The mixture was stirred at $0{ }^{\circ} \mathrm{C}$ for $2 \mathrm{~h}$ and at $25{ }^{\circ} \mathrm{C}$ for $6 \mathrm{~h}$. After cooling to $0{ }^{\circ} \mathrm{C}$, the reaction mixture was quenched with saturated solution of aqueous $\mathrm{Na}_{2} \mathrm{SO}_{4}(20 \mathrm{~mL})$ and was extracted with ethyl acetate $(3 \mathrm{x}$ $100 \mathrm{~mL})$, the combined organic extracts were washed with brine $(2 \times 50 \mathrm{~mL})$, dried over $\mathrm{MgSO}_{4}$, concentrated under reduced pressure and purified by flash chromatography (silica, 35:65 ethyl acetate in hexane) to give the corresponding diol $(5.32 \mathrm{~g}, 15.6 \mathrm{mmol}$, $85 \%)$ as a white solid: $\mathrm{R}_{\mathrm{f}}=0.5$ (70\% ethyl acetate in hexane); ${ }^{1} \mathrm{H}$ NMR $(400 \mathrm{MHz}$, $\left.\mathrm{CDCl}_{3}\right) \delta 5.57(1 \mathrm{H}, \mathrm{dd}, J=4.0,3.6 \mathrm{~Hz}), 4.06(1 \mathrm{H}, \mathrm{dd}, J=5.5,10.6 \mathrm{~Hz}), 3.46(1 \mathrm{H}, \mathrm{d}, J=$ $10.8 \mathrm{~Hz}), 3.40-3.30(2 \mathrm{H}, \mathrm{m}), 2.37(1 \mathrm{H}, \mathrm{dd}, J=5.6 \mathrm{~Hz}), 2.28(1 \mathrm{H}, \mathrm{m}), 2.17-2.14(2 \mathrm{H}, \mathrm{m})$, 1.97-1.86 $(2 \mathrm{H}, \mathrm{m}), 1.81-1.75(1 \mathrm{H}, \mathrm{m}), 1.69-1.63(2 \mathrm{H}, \mathrm{m}), 1.57(1 \mathrm{H}, \mathrm{m}), 1.32(3 \mathrm{H}, \mathrm{s}), 1.07$ $(3 \mathrm{H}, \mathrm{s}), 0.90(9 \mathrm{H}, \mathrm{s}), 0.06(3 \mathrm{H}, \mathrm{s}), 0.04(3 \mathrm{H}, \mathrm{s}) ;{ }^{13} \mathrm{C}$ NMR $\left(100 \mathrm{MHz}, \mathrm{CDCl}_{3}\right) \delta 144.2$, 123.8, 78.6, 78.2, 67.5, 46.3, 39.2, 35.2, 27.4, 26.5, 26.0, 25.2, 21.9, 19.8, 18.2, -3.8, -4.6; HRMS calcd. for $\mathrm{C}_{19} \mathrm{H}_{36} \mathrm{O}_{3} \mathrm{Si}\left(\mathrm{M}+\mathrm{Na}^{+}\right)$363.2331, found 363.2361.

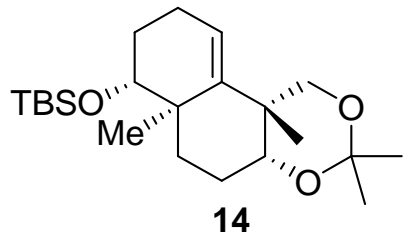

Alkene 14: A stirred solution of diol $(5.0 \mathrm{~g}, 14.7 \mathrm{mmol})$ in $\mathrm{CH}_{2} \mathrm{Cl}_{2}(30 \mathrm{~mL})$ was treated with excess 2,2-dimethoxy propane $(10 \mathrm{~mL}, 81.32 \mathrm{mmol})$ and CSA $(34 \mathrm{mg}, 0.146 \mathrm{mmol})$ at $0{ }^{\circ} \mathrm{C}$. After stirring for $30 \mathrm{~min}$ the reaction mixture was quenched with a saturated solution of sodium bicarbonate $(10 \mathrm{~mL})$ and extracted with $\mathrm{CH}_{2} \mathrm{Cl}_{2}(100 \mathrm{~mL})$. The organic layer was washed with brine $(30 \mathrm{~mL})$, dried over $\mathrm{MgSO}_{4}$, concentrated under reduced pressure and purified by flash chromatography (silica, 2:98 ethyl acetate in hexanes) to give $14(5.3 \mathrm{~g}, 13.9 \mathrm{mmol}$, 95\%). 14: White solid; $\mathrm{R}_{\mathrm{f}}=0.8$ (10\% ethyl acetate in hexanes). ${ }^{1} \mathrm{H}$ NMR $(400 \mathrm{MHz}$, $\left.\mathrm{CDCl}_{3}\right) \delta 5.46(1 \mathrm{H}, \mathrm{t}, J=3.6 \mathrm{~Hz}), 3.92(1 \mathrm{H}, \mathrm{d}, J=11.6 \mathrm{~Hz}), 3.67(1 \mathrm{H}, \mathrm{t}, J=5.6 \mathrm{~Hz})$, $3.39(1 \mathrm{H} \mathrm{dd}, J=12.0,3.6 \mathrm{~Hz}), 3.30(1 \mathrm{H}, \mathrm{d}, J=11.6 \mathrm{~Hz}), 2.23-2.09(2 \mathrm{H}, \mathrm{m}), 1.91-1.73$ $(4 \mathrm{H}, \mathrm{m}), 1.62(1 \mathrm{H}, \mathrm{m}), 1.42(3 \mathrm{H}, \mathrm{s}), 1.41(3 \mathrm{H}, \mathrm{s}), 1.26(1 \mathrm{H}, \mathrm{m}), 1.23(3 \mathrm{H}, \mathrm{s}), 1.12(3 \mathrm{H}, \mathrm{s})$, $0.90(9 \mathrm{H}, \mathrm{s}), 0.06(3 \mathrm{H}, \mathrm{s}), 0.05(3 \mathrm{H}, \mathrm{s}),{ }^{13} \mathrm{C} \mathrm{NMR}\left(100 \mathrm{MHz}, \mathrm{CDCl}_{3}\right) \delta 145.1,121.0$, $98.4,77.3,74.2,68.8,39.0,38.9,30.7,26.9,26.6,26.3,26.0,24.8,24.5,23.7,20.3,18.2$ -3.7, -4.6; HRMS calcd. for $\mathrm{C}_{22} \mathrm{H}_{40} \mathrm{O}_{3} \mathrm{Si}\left(\mathrm{M}+\mathrm{Na}^{+}\right)$403.2644, found 403.2674 . 


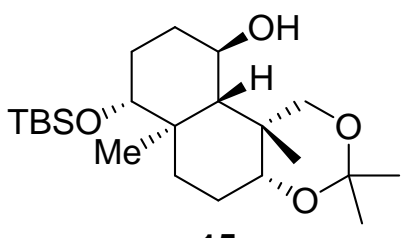

15

Alcohol 15: A stirred solution of compound 14 (6.0 g, 15.8 mmol) in dry THF $(40 \mathrm{~mL})$ at $0{ }^{\circ} \mathrm{C}$ was treated with $1 \mathrm{M}$ BH3:THF solution $(31.6 \mathrm{~mL}, 31.6 \mathrm{mmol})$. The mixture was kept at $0{ }^{\circ} \mathrm{C}$ for $6 \mathrm{~h}$ and then $25{ }^{\circ} \mathrm{C}$ overnight. A mixture of aqueous $\mathrm{NaOH}(3 \mathrm{~N}, 42 \mathrm{~mL})$ and $\mathrm{H}_{2} \mathrm{O}_{2}(30 \%, 42 \mathrm{~mL})$ was added at $0{ }^{\circ} \mathrm{C}$ and the reaction was stirred for $6 \mathrm{~h}$. The reaction mixture

was extracted with ethyl acetate $(2 \times 150 \mathrm{~mL})$, the combined organic extracts were washed with brine $(100 \mathrm{~mL})$, dried over $\mathrm{MgSO}_{4}$, concentrated under reduced pressure and purified by column chromatography (silica, 8:92 ethyl acetate in hexanes) to give $\mathbf{1 5}$ (3.39 g, $8.5 \mathrm{mmol}, 54 \%$ ). 15: White solid; $\mathrm{R}_{\mathrm{f}}=0.45$ (30\% ethyl acetate in hexanes). ${ }^{1} \mathrm{H}$ NMR $\left(400 \mathrm{MHz}, \mathrm{CDCl}_{3}\right) \mathrm{d}(4.02,1 \mathrm{H}, \mathrm{d}, J=11.2 \mathrm{~Hz}), 3.84(1 \mathrm{H}, \mathrm{m}), 3.63(1 \mathrm{H}, \mathrm{d}, J=11.2$ $\mathrm{Hz}), 3.45(1 \mathrm{H}, \mathrm{dd}, J=6.0,3.2 \mathrm{~Hz}), 3.19(1 \mathrm{H}, \mathrm{dd}, J=9.6,5.0 \mathrm{~Hz}), 1.93(1 \mathrm{H}, \mathrm{m}), 1.80(1 \mathrm{H}$, m), 1.72-1.56 (5H, m), $1.43(3 \mathrm{H}, \mathrm{s}), 1.37(3 \mathrm{H}, \mathrm{s}), 1.33(1 \mathrm{H}, \mathrm{m}), 1.34(3 \mathrm{H}, \mathrm{s}), 1.21(3 \mathrm{H}, \mathrm{s}$ ), $1.05(1 \mathrm{H}, \mathrm{d}, J=10.8), 0.95(1 \mathrm{H}, \mathrm{d}, J=6.0 \mathrm{~Hz}), 0.87(9 \mathrm{H}, \mathrm{s}), 0.05(3 \mathrm{H}, \mathrm{s}), 0.03(3 \mathrm{H}, \mathrm{s})$. ${ }^{13} \mathrm{C} \mathrm{NMR}\left(100 \mathrm{M} \mathrm{Hz}, \mathrm{CDCl}_{3}\right) \delta 99.8,80.2,75.6,68.5,64.6,52.7,39.3,38.4,36.0,32.9$, 29.7, 28.6, 25.9, 25.3, 24.6, 23.0, 18.2, 15.9, -3.5, -4.7; HRMS calcd. for $\mathrm{C}_{22} \mathrm{H}_{42} \mathrm{O}_{4} \mathrm{Si}(\mathrm{M}+$ $\mathrm{Na}^{+}$) 421.2750, found 421.2781.

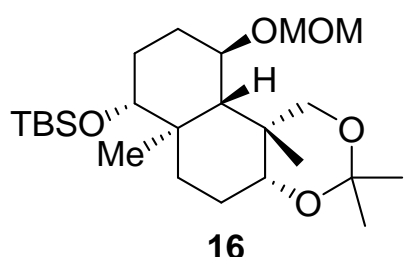

combined organic extracts were washed with brine $(50 \mathrm{~mL})$, dried over $\mathrm{MgSO}_{4}$, concentrated under reduced pressure and purified by column chromatography (silica, 6:94 ethyl acetate in hexanes), to give 16 (2.99 g, $6.8 \mathrm{mmol}, 90 \%)$. 16: Colorless liquid; $\mathrm{R}_{\mathrm{f}}=0.55$ (30\% ethyl acetate in hexanes); ${ }^{1} \mathrm{H} \mathrm{NMR}\left(400 \mathrm{MHz}, \mathrm{CDCl}_{3}\right) \delta 4.47(1 \mathrm{H}, \mathrm{d}, J=$ $6.8 \mathrm{~Hz}), 4.60(1 \mathrm{H}, \mathrm{d}, J=6.8 \mathrm{~Hz}), 3.96(1 \mathrm{H}, \mathrm{d}, J=11.2 \mathrm{~Hz}), 3.62(1 \mathrm{H}, \mathrm{dt}, J=10.8$, $4.4 \mathrm{~Hz}), 3.47(1 \mathrm{H}, \mathrm{d}, J=11.2 \mathrm{~Hz}), 3.43(1 \mathrm{H}, \mathrm{m}), 3.36(3 \mathrm{H}, \mathrm{s}), 3.18(1 \mathrm{H}, \mathrm{dd}, J=10.8,4.4$ $\mathrm{Hz}), 2.17(1 \mathrm{H}, \mathrm{m}), 1.78(1 \mathrm{H}, \mathrm{m}), 1.71-1.46(4 \mathrm{H}, \mathrm{m}), 1.42(3 \mathrm{H}, \mathrm{s}), 1.40-1.25(2 \mathrm{H}, \mathrm{m})$, $(3 \mathrm{H}, \mathrm{s}), 1.31(3 \mathrm{H}, \mathrm{s}), 1.21(3 \mathrm{H}, \mathrm{s}), 1.05(1 \mathrm{H}, \mathrm{d}, J=10.8 \mathrm{~Hz}), 0.87(9 \mathrm{H}, \mathrm{s}), 0.04(3 \mathrm{H}, \mathrm{s})$, 0.02 ( $3 \mathrm{H}, \mathrm{s}) ;{ }^{13} \mathrm{C}$ NMR $\left(100 \mathrm{MHz}, \mathrm{CDCl}_{3}\right) \delta 99.8,96.1,80.2,76.3,75.5,64.5,56.1$, 51.6, 39.4., 38.5, 32.9, 32.0, 29.5, 28.1, 25.9, 25.1, 24.6, 22.8, 18.2, 16.0, -3.5, -4.8; HRMS calcd. for $\mathrm{C}_{24} \mathrm{H}_{46} \mathrm{O}_{5} \mathrm{Si}\left(\mathrm{M}+\mathrm{Na}^{+}\right) 465.3012$, found 465.3032 .

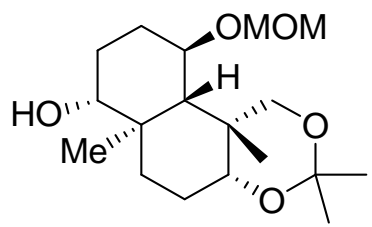

Ketone 6 Precursor: A stirred solution of compound 16 (2.9 g, $6.56 \mathrm{mmol})$ in anhydrous THF $(15 \mathrm{~mL})$ was treated at $0{ }^{\circ} \mathrm{C}$ with $1 \mathrm{M}$ TBAF in THF $(13.10 \mathrm{~mL}, 13.10 \mathrm{mmol})$. The resulting mixture was heated at $50{ }^{\circ} \mathrm{C}$ for $48 \mathrm{~h}$ and then quenched with aqueous ammonium chloride and extracted with ethyl acetate $(2 \times 70 \mathrm{~mL})$ the combined organic layers were washed with brine $(50 \mathrm{~mL})$, dried over $\mathrm{MgSO}_{4}$, concentrated under reduced pressure and purified by column chromatography (silica, 
16:84 ethyl acetate in hexanes) to give the alcohol $(2.04 \mathrm{~g}, 6.23 \mathrm{mmol}, 95 \%): \mathrm{R}_{\mathrm{f}}=0.25$ (30\% ethyl acetate in hexane).

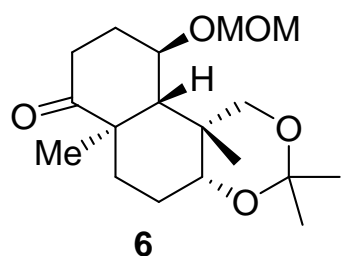

6

Ketone 6: To a stirred solution of the corresponding alcohol (2.0 g, $6.0 \mathrm{mmol})$ in dry $\mathrm{CH}_{2} \mathrm{Cl}_{2}: \mathrm{DMSO}(4: 1)(15 \mathrm{~mL})$ at $0{ }^{\circ} \mathrm{C}$ was added IBX (4.6.g, $12.0 \mathrm{mmol})$. The resulting mixture was stirred at $25{ }^{\circ} \mathrm{C}$ for $24 \mathrm{~h}$ and then quenched with aqueous sodium thiosulfate (15 $\mathrm{mL})$ and extracted with $\mathrm{CH}_{2} \mathrm{Cl}_{2}(2 \times 70 \mathrm{~mL})$. The combined organic layers were washed with brine $(50 \mathrm{~mL})$, dried over $\mathrm{MgSO}_{4}$, concentrated under reduced pressure and purified by column chromatography (silica,16:84 ethyl acetate in hexanes), to give 6 (1.99 g, $5.82 \mathrm{mmol}, 97 \%)$. 6: White solid; $\mathrm{R}_{\mathrm{f}}=0.5$ (30\% ethyl acetate in hexanes); IR (film) ? ${ }_{\max } 2936,1710,1037 ;{ }^{1} \mathrm{H}$ NMR $\left(400 \mathrm{MHz}, \mathrm{CDCl}_{3}\right) \delta 4.67(1 \mathrm{H}, \mathrm{d}, J=6.8 \mathrm{~Hz}), 4.64(1 \mathrm{H}, \mathrm{d}, J=6.8 \mathrm{~Hz}) 4.08(1 \mathrm{H}, \mathrm{ddd}, J=$ 10.4, 10.0, $4.4 \mathrm{~Hz}), 3.99(1 \mathrm{H}, \mathrm{d}, J=11.2 \mathrm{~Hz}), 3.53(1 \mathrm{H}, \mathrm{d}, J=11.2 \mathrm{~Hz}), 3.45(1 \mathrm{H}, \mathrm{m})$, $3.38(3 \mathrm{H}, \mathrm{s}), 2.68(1 \mathrm{H}, \mathrm{m}), 2.48-2.41(2 \mathrm{H}, \mathrm{m}), 2.31(1 \mathrm{H}, \mathrm{m}), 1.78(1 \mathrm{H}, \mathrm{m}), 1.66-1.57$ $(2 \mathrm{H}, \mathrm{m}), 1.54(1 \mathrm{H}, \mathrm{d}, J=10.8 \mathrm{~Hz}), 1.51(3 \mathrm{H}, \mathrm{s}), 1.39(3 \mathrm{H}, \mathrm{s}), 1.35(3 \mathrm{H}, \mathrm{s}), 1.33(1 \mathrm{H}, \mathrm{m})$, $1.26(3 \mathrm{H}, \mathrm{s}) ;{ }^{13} \mathrm{C}$ NMR $\left(100 \mathrm{M} \mathrm{Hz}, \mathrm{CDCl}_{3}\right) \delta 212.7,100.23,96.4,75.2,74.3,64.7,56.3$, $50.81,47.25,39.7,35.0,32.1,27.4,25.3,24.4,24.3,24.0,22.2$; HRMS calcd. for $\mathrm{C}_{18} \mathrm{H}_{30} \mathrm{O}_{5}\left(\mathrm{M}+\mathrm{Na}^{+}\right)$349.1991, found 349.1984.

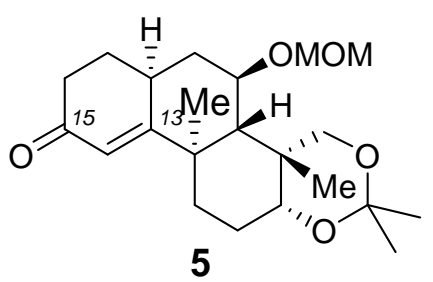

extracted with ethyl acetate $(2 \times 50 \mathrm{~mL})$. The combined organic extracts were washed with brine $(20 \mathrm{~mL})$, dried over $\mathrm{MgSO}_{4}$, concentrated under reduced pressure and purified by column chromatography to give $17(1.4 \mathrm{~g}, 4.0 \mathrm{mmol}, 89 \%)$, which was used in the next step. Compound $17(1.4 \mathrm{~g}, 4.0 \mathrm{mmol})$ was treated with methyl vinyl ketone $(1.38$ $\mathrm{mL}, 16.6 \mathrm{mmol})$ and $\mathrm{Et}_{3} \mathrm{~N}(1.28 \mathrm{~mL}, 9.2 \mathrm{mmol})$ at $0{ }^{\circ} \mathrm{C}$. After stirring for $4 \mathrm{~h}$, the reaction mixture was poured into water and extracted with ethyl acetate $(2 \times 50 \mathrm{~mL})$. The combined organic extracts were washed with water and brine, then dried over $\mathrm{MgSO}_{4}$. Removal of the solvent in vacuo gave a residue, which was dissolved in dry $\mathrm{MeOH}(5$ $\mathrm{mL})$ under argon at $0{ }^{\circ} \mathrm{C}$ and treated with a solution of $\mathrm{NaOMe}$ in methanol $(23 \mathrm{~mL}, 1$ M). After stirring at $0{ }^{\circ} \mathrm{C}$ for $4 \mathrm{~h}$, the reaction mixture was allowed to warm to $25^{\circ} \mathrm{C}$ and stirred overnight. Then the reaction mixture was quenched with water $(10 \mathrm{~mL})$, methanol was removed under reduced pressure and the residue was extracted with ethyl acetate $(2 \mathrm{x}$ $50 \mathrm{~mL}$ ). The combined organic extracts were washed with brine, dried over $\mathrm{MgSO}_{4}$, concentrated under reduced pressure and purified by flash chromatography (silica, 35:65.ethyl acetate in hexanes) to give $5(1.05 \mathrm{~g}, 2.8 \mathrm{mmol}, 72 \%)$. 5: White solid $\mathrm{R}_{\mathrm{f}}=$ 0.45 (50\% ethyl acetate in hexanes); IR (film) ? $\max 2937,1662 ; 1 \mathrm{H} \mathrm{NMR}(400 \mathrm{MHz}$, $\left.\mathrm{CDCl}_{3}\right) \delta 5.92(1 \mathrm{H}, \mathrm{s}), 4.76(1 \mathrm{H}, \mathrm{d}, J=6.8 \mathrm{~Hz}), 4.72(1 \mathrm{H}, \mathrm{d}, J=6.8 \mathrm{~Hz}) 4.14(1 \mathrm{H}, \mathrm{m})$, 
$4.03(1 \mathrm{H}, \mathrm{d}, J=11.6 \mathrm{~Hz}), 3.61(1 \mathrm{H}, \mathrm{d}, J=11.6, \mathrm{~Hz}), 3.45(1 \mathrm{H}, \mathrm{m}), 3.41(3 \mathrm{H}, \mathrm{s}), 2.70$ $(1 \mathrm{H}, \mathrm{m}), 2.53(1 \mathrm{H}, \mathrm{dd}, J=14.0,3.6 \mathrm{~Hz}), 2.39(1 \mathrm{H}, \mathrm{m}), 2.08-1.99(3 \mathrm{H}, \mathrm{m}), 1.90-1.72(3 \mathrm{H}$, m), $1.69(3 \mathrm{H}, \mathrm{s}), 1.64(3 \mathrm{H}, \mathrm{s}), 1.61(1 \mathrm{H}, \mathrm{m}), 1.48(1 \mathrm{H}, \mathrm{d}, J=10.8 \mathrm{~Hz}), 1.39(3 \mathrm{H}, \mathrm{s}), 1.38$ $(3 \mathrm{H}, \mathrm{s}), 1.26(1 \mathrm{H}, \mathrm{m}) .{ }^{13} \mathrm{C}$ NMR $\left(100 \mathrm{M} \mathrm{Hz}, \mathrm{CDCl}_{3}\right) \delta 200.1,170.6,124.0,99.7,96.4$, 75.3, 73.4, 69.5, 64.2, 56.2, 53.2, 48.4, 41.2, 39.2, 38.6, 33.2, 32.4, 29.0, 26.6, 25.4, 25.2, 23.5; HRMS calcd. for $\mathrm{C}_{22} \mathrm{H}_{34} \mathrm{O}_{5}\left(\mathrm{M}+\mathrm{Na}^{+}\right)$401.2304, found 401.2334.

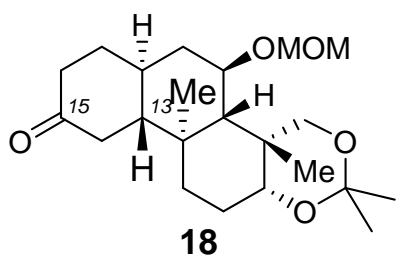

18

Ketone 18: A solution of 5 (500 mg, $1.32 \mathrm{mmol})$ in dry THF (3 $\mathrm{mL})$ and dry $\mathrm{EtOH}(0.2 \mathrm{~mL})$ was added drop wise to liq. $\mathrm{NH}_{3}(8$ $\mathrm{mL})$ at $-78{ }^{\circ} \mathrm{C}$ under argon. The resulting solution was treated with lithium (184 mg, $26.4 \mathrm{mmol})$ portion wise $(4 \mathrm{x} \mathrm{46,} \mathrm{mg})$ over $1 \mathrm{~h}$. After stirring for $4 \mathrm{~h}$ solid ammonium chloride was added and the mixture was warmed slowly to $25^{\circ} \mathrm{C}$ allowing the excess ammonia to be evaporated. The resulting mixture was diluted with water $(5 \mathrm{~mL})$ and extracted with ethyl acetate $(2 \times 50 \mathrm{~mL})$. The combined organic extracts were washed with water $(10 \mathrm{~mL})$ and brine $(10 \mathrm{~mL})$, dried over $\mathrm{MgSO}_{4}$, concentrated under reduced pressure and purified by flash chromatography (silica, 22:78 ethyl acetate in hexanes) to give 18 (449 mg, $1.18 \mathrm{mmol}, 90 \%)$. 18: White solid; $\mathrm{R}_{\mathrm{f}}=0.5$ (50\% ethyl acetate in hexanes); IR (film) ? $?_{\max } 2918,1665,1034 ; 1 \mathrm{H} \mathrm{NMR}\left(400 \mathrm{MHz}, \mathrm{CDCl}_{3}\right) \delta 4.72$ $(1 \mathrm{H}, \mathrm{d}, J=6.8 \mathrm{~Hz}), 4.65(1 \mathrm{H}, \mathrm{d}, J=6.8 \mathrm{~Hz}), 3.95(1 \mathrm{H}, \mathrm{d}, J=11.6 \mathrm{~Hz}), 3.73(1 \mathrm{H}, \mathrm{dt}, J=$ $11.2,4.0 \mathrm{~Hz}), 3.52(1 \mathrm{H}, \mathrm{d}, J=11.6 \mathrm{~Hz}), 3.46(1 \mathrm{H}, \mathrm{dd}, J=4.8,3.2 \mathrm{~Hz}), 3.39(3 \mathrm{H}, \mathrm{s})$, 2.40-2.27 $(4 \mathrm{H}, \mathrm{m}), 2.09(1 \mathrm{H}, \mathrm{t}, J=13.6 \mathrm{~Hz}), 2.0(1 \mathrm{H}, \mathrm{m}), 1.83-1.64(3 \mathrm{H}, \mathrm{m}), 1.51(1 \mathrm{H}$, $\mathrm{m}), 1.38-1.25(3 \mathrm{H}, \mathrm{m}), 1.40(3 \mathrm{H}, \mathrm{s}), 1.36(3 \mathrm{H}, \mathrm{s}), 1.30(3 \mathrm{H}, \mathrm{s}), 1.25(3 \mathrm{H}, \mathrm{s}) \cdot 1.21-1.03$ $(3 \mathrm{H}, \mathrm{m}) ;{ }^{13} \mathrm{CNMR}\left(100 \mathrm{MHz}, \mathrm{CDCl}_{3}\right) \delta 212.3,100.1,96.3,76.2,74.6,64.7,56.2,55.7$, 53.8, 41.4, 41.2, 40.94, 38.7, 37.0, 34.7, 33.6, 32.8, 28.4, 24.5, 24.5, 22.5, 17.5; HRMS calcd. for $\mathrm{C}_{22} \mathrm{H}_{37} \mathrm{O}_{5}\left(\mathrm{M}+\mathrm{Na}^{+}\right)$404.2539, found 404.2509.

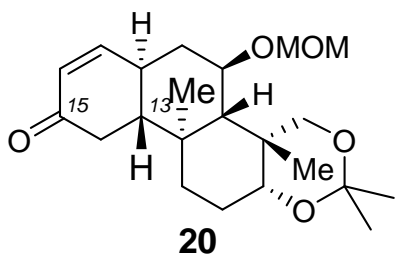

Enone 20: A solution of $\mathbf{1 8}(400 \mathrm{mg}, 1.05 \mathrm{mmol})$ in dry THF (4 $\mathrm{mL})$ was treated with $1 \mathrm{M} \mathrm{NaHMDS}$ in THF $(1.5 \mathrm{~mL})$, drop wise at $-78{ }^{\circ} \mathrm{C}$ under argon. The mixture was stirred for $30 \mathrm{~min}$ and then treated with a solution of $\mathrm{PhSeCl}(401 \mathrm{mg}, 2.1 \mathrm{mmol})$ in THF $(2 \mathrm{~mL})$. After stirring for $1 \mathrm{~h}$ the reaction mixture was quenched with saturated solution of aqueous ammonium chloride $(2 \mathrm{~mL})$ and extracted with ethyl acetate $(2 \times 8 \mathrm{~mL})$, the combined organic extracts were washed with brine $(3 \mathrm{~mL})$, and dried over $\mathrm{MgSO}_{4}$, concentrated under reduced pressure and purified by flash chromatography (silica, 12:88 ethyl acetate in hexanes) to give the selenide ( $417 \mathrm{mg}, 0.78 \mathrm{mmol} 75 \%$ ) This selenide was dissolved in THF: $\mathrm{H}_{2} \mathrm{O}(2: 1)(4 \mathrm{~mL})$ and treated with $\mathrm{NaIO}_{4}(333 \mathrm{mg}, 1.56 \mathrm{mmol})$ at $0{ }^{\circ} \mathrm{C}$ and stirred for $2 \mathrm{~h}$ at room temperature. Then the reaction mixture was diluted with water $(2 \mathrm{~mL})$ and extracted with ethyl acetate $(2 \times 10 \mathrm{~mL})$. The combined organic extracts were washed with water $(5 \mathrm{~mL})$ and brine $(5 \mathrm{~mL})$, dried over $\mathrm{MgSO}_{4}$, concentrated under reduced pressure and purified by flash chromatography (silica, 20:80 ethyl acetate in hexanes) to give $20(265 \mathrm{mg}, 0.70 \mathrm{mmol}, 90 \%)$. 20: White solid; $\mathrm{R}_{\mathrm{f}}=0.5(50 \%$ ethyl acetate in hexane); IR (film) ? ${ }_{\max } 2937,1682,1038 ; 1 \mathrm{H} \mathrm{NMR}\left(400 \mathrm{MHz}, \mathrm{CDCl}_{3}\right) \delta 6.67$ (1H, dd, $J$ 
$=9.6,1.6 \mathrm{~Hz}), 5.95(1 \mathrm{H}, \mathrm{dd}, J=9.6,2, \mathrm{~Hz}), 4.76(1 \mathrm{H}, \mathrm{d}, J=6.8 \mathrm{~Hz}), 4.64(1 \mathrm{H}, \mathrm{d}, J=6.8$ $\mathrm{Hz}), 3.92(1 \mathrm{H}, \mathrm{d}, J=11.2 \mathrm{~Hz}), 3.78(1 \mathrm{H}, \mathrm{ddd}, J=10.8,10.4,4.4 \mathrm{~Hz}), 3.51-3.47(2 \mathrm{H}, \mathrm{m})$, $3.40(3 \mathrm{H} \mathrm{s}), 2.54-2.38(2 \mathrm{H}, \mathrm{m}), 2.14(1 \mathrm{H}, \mathrm{dd}, J=16.0,14.4 \mathrm{~Hz}), 1.85-1.66(3 \mathrm{H}, \mathrm{m}), 1.62-$ $1.48(2 \mathrm{H}, \mathrm{m}), 1.43-1.21(3 \mathrm{H}, \mathrm{m}), 1.40(3 \mathrm{H}, \mathrm{s}), 1.36(3 \mathrm{H}, \mathrm{s}), 1.30(3 \mathrm{H}, \mathrm{s}), 1.29(3 \mathrm{H}, \mathrm{s}) ;{ }^{13} \mathrm{C}$ NMR (100 MHz, $\left.\mathrm{CDCl}_{3}\right) \delta 200.3,154.1,128.5,100.3,96.5,76.6,74.4,64.6,56.2,53.8$, 53.6, 39.7, 38.9, 38.6, 36.5, 35.8, 32.2, 28.3, 24.4, 24.3, 22.2, 18.3; HRMS calcd. for $\mathrm{C}_{22} \mathrm{H}_{34} \mathrm{O}_{5}\left(\mathrm{M}+\mathrm{Na}^{+}\right)$401.2298, found 401.2307.

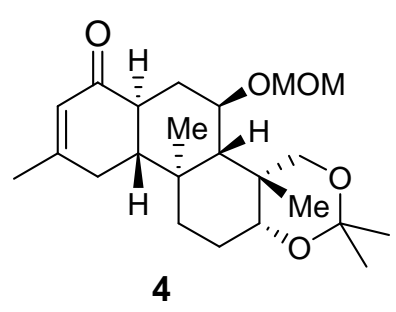

Enone 4: To a solution of $\mathbf{2 0}(200 \mathrm{mg}, 0.52 \mathrm{mmol})$ in dry ether $(4 \mathrm{~mL})$ at $0{ }^{\circ} \mathrm{C}$ was added $\mathrm{MeLi}(1.04 \mathrm{~mL}, 1 \mathrm{M}$ in ether). The mixture was stirred for $30 \mathrm{~min}$ and was quenched with a saturated solution of aqueous ammonium chloride $(2 \mathrm{~mL})$ and extracted with ethyl acetate $(2 \times 5 \mathrm{~mL})$, the combined organic extracts were washed with brine ( $4 \mathrm{~mL})$, dried over $\mathrm{MgSO}_{4}$, and purified by flash chromatography to give the tertiary alcohol (182 $\mathrm{mg}, 0.46 \mathrm{mmol}, 90 \%)$. This alcohol $(182 \mathrm{mg}, 0.46 \mathrm{mmol})$ was dissolved in anhydrous dichloromethane $(3 \mathrm{~mL})$, containing MS $3 \mathrm{~A}(40 \mathrm{mg})$ and treated with PCC (198 mg, $0.92 \mathrm{mmol}$ ) at $0{ }^{\circ} \mathrm{C}$. After stirring for $2 \mathrm{~h}$ the reaction mixture was filtered through silica gel, and the filtrate was concentrated in vacuo. The residue was purified by flash chromatography (22:78 ethyl acetate in hexanes) to give $4(148 \mathrm{mg}, 0.35 \mathrm{mmol}$, 78\%). 4: White solid; $R_{\mathrm{f}}=0.45$ (45\% ethyl acetate in hexanes); IR (film) ? $\max 22925$, 1666; ${ }^{1} \mathrm{H}$ NMR $\left(400 \mathrm{MHz}, \mathrm{CDCl}_{3}\right) \delta 5.83(1 \mathrm{H}, \mathrm{s}), 4.77(1 \mathrm{H}, \mathrm{d}, J=6.8 \mathrm{~Hz}), 4.64(1 \mathrm{H}, \mathrm{d}, J$ $=6.8 \mathrm{~Hz}), 3.95(1 \mathrm{H} \mathrm{d}, J=11.6 \mathrm{~Hz}), 3.73(1 \mathrm{H}, \mathrm{ddd}, J=11.2,10.4,4.4 \mathrm{~Hz}), 3.59(1 \mathrm{H}, \mathrm{d}, J=$ $11.6 \mathrm{~Hz}), 3.47(1 \mathrm{H}, \mathrm{dd}, J=5.2,3.2 \mathrm{~Hz}), 3.42(3 \mathrm{H}, \mathrm{s}), 2.77(1 \mathrm{H}, \mathrm{m}), 2.26-2.13(3 \mathrm{H}, \mathrm{m})$, $1.96(3 \mathrm{H}, \mathrm{s}), 1.89-1.51(6 \mathrm{H}, \mathrm{m}), 1.41(3 \mathrm{H}, \mathrm{s}), 1.37(3 \mathrm{H}, \mathrm{s}), 1.32(3 \mathrm{H}, \mathrm{s}), 1.27(3 \mathrm{H}, \mathrm{s}), 1.22$ $(1 \mathrm{H}, \mathrm{m}) ;{ }^{13} \mathrm{C}$ NMR $\left(100 \mathrm{M} \mathrm{Hz}, \mathrm{CDCl}_{3}\right) \delta 200.1,161.4,125.3,100.0,95.7,75.6,74.8$, 64.6, 56.6, 53.9, 52.0, 43.8, 38.6, 37.0, 34.0, 33.0, 31.2, 29.8, 28.7, 24.7, 24.6, 22.7, 18.1; HRMS calcd. for $\mathrm{C}_{23} \mathrm{H}_{36} \mathrm{O}_{5}\left(\mathrm{M}+\mathrm{Na}^{+}\right)$415.2455, found 415.2468. 


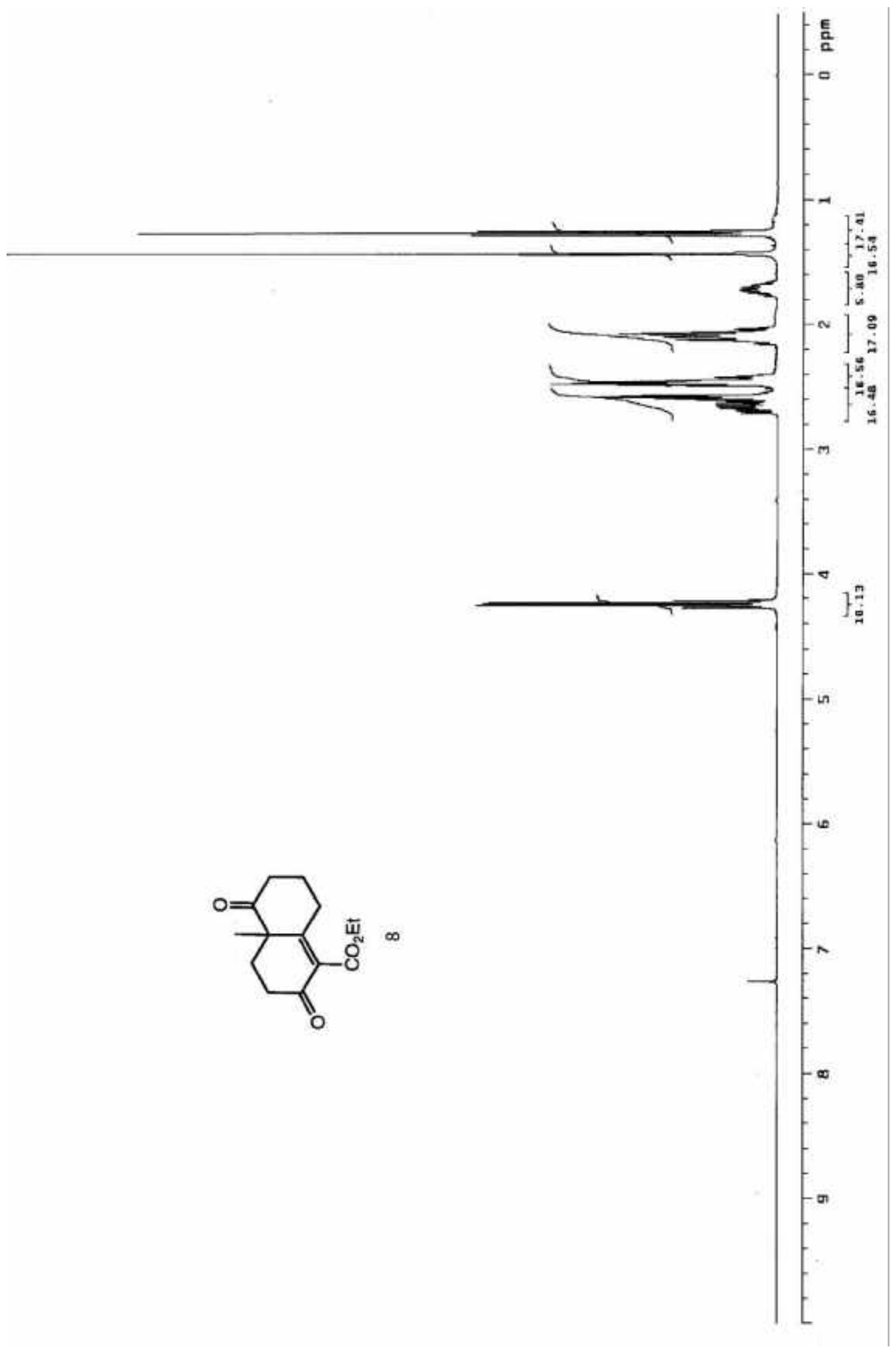




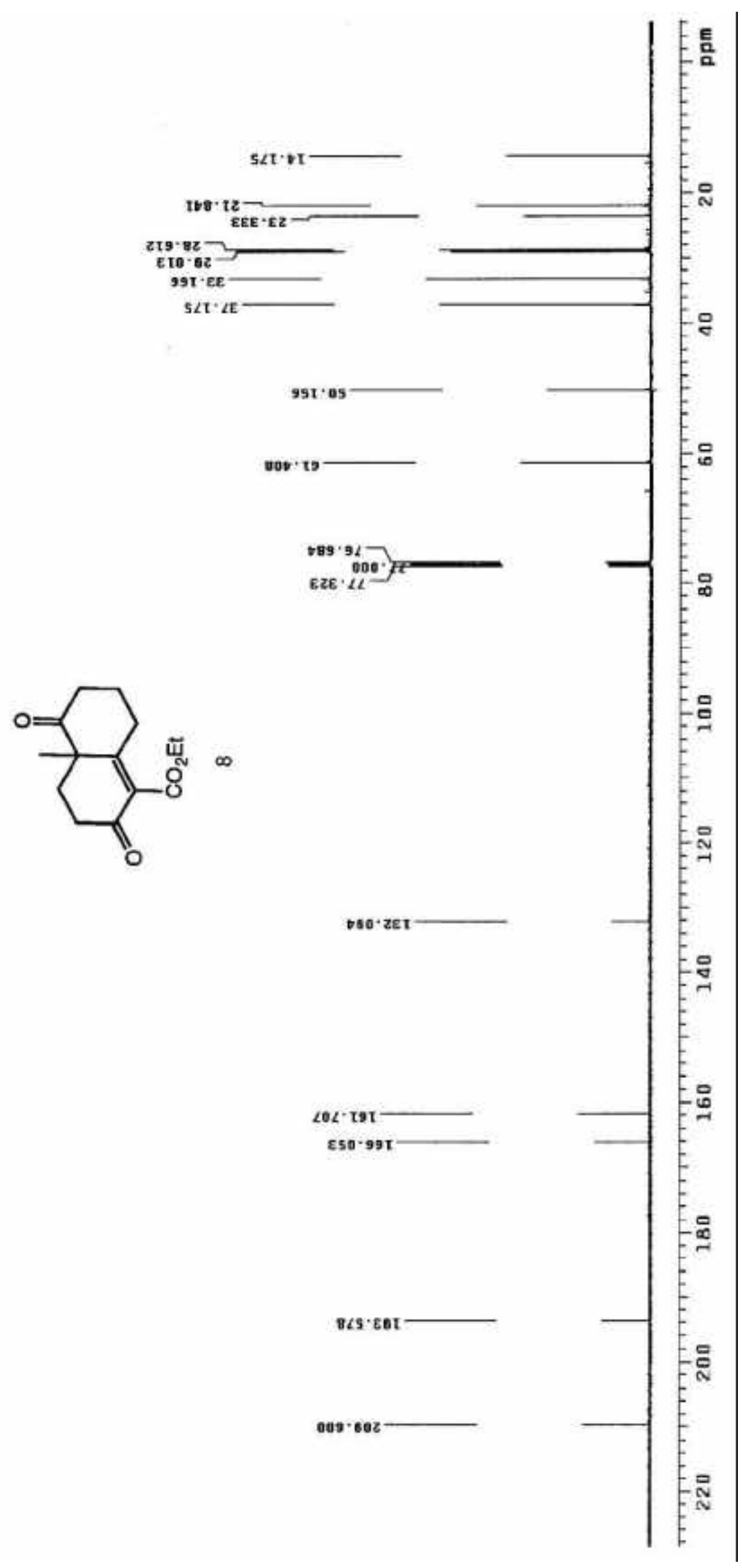




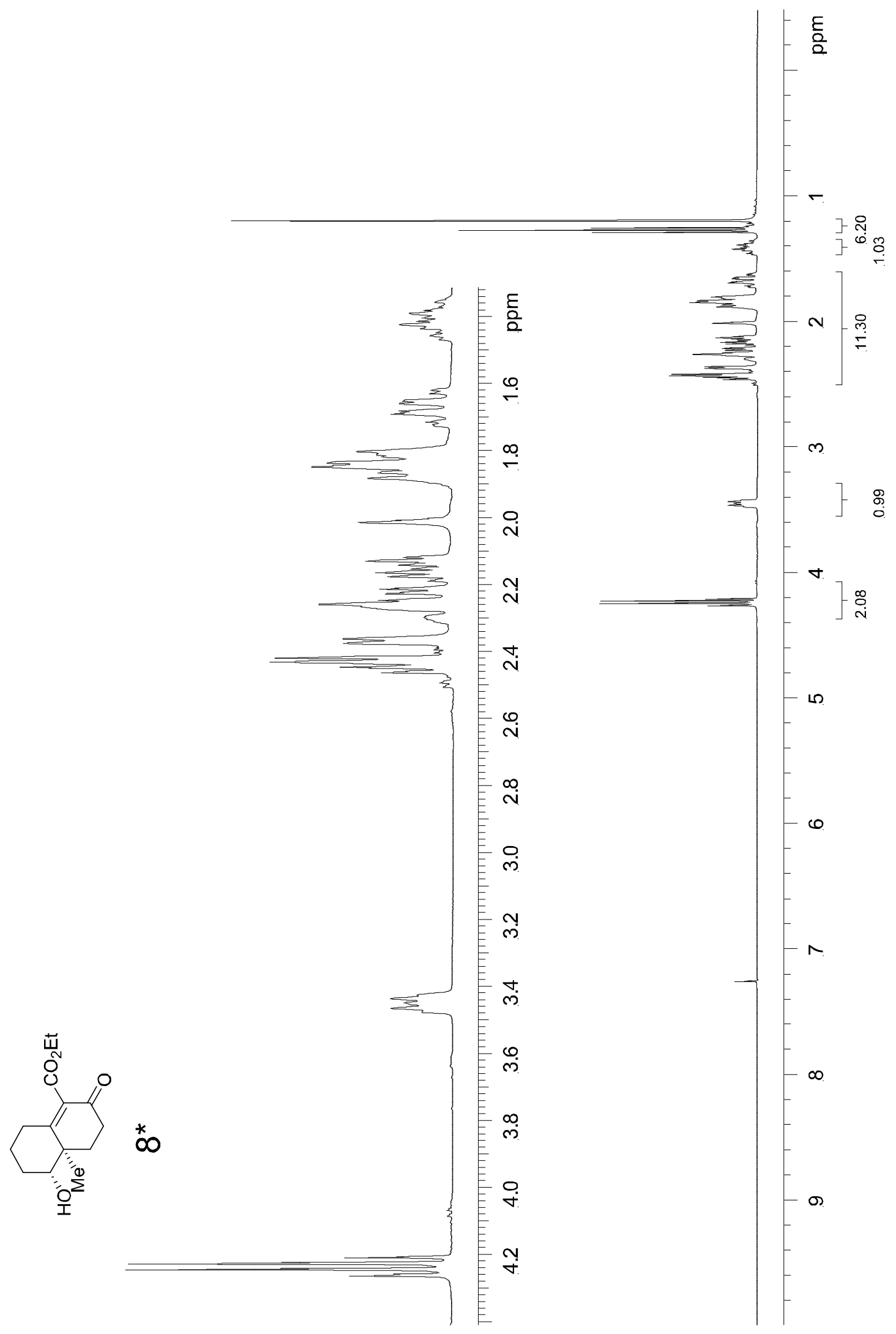




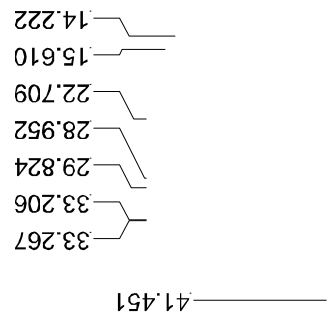

оะย๋เด

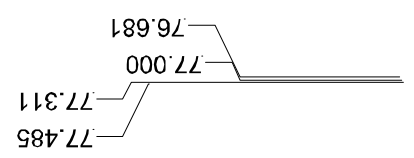

698เレレ-

G99 $\downarrow 91-$ $8 \angle 8991-$

乙E० $\varsigma 6 \mathrm{~L}$

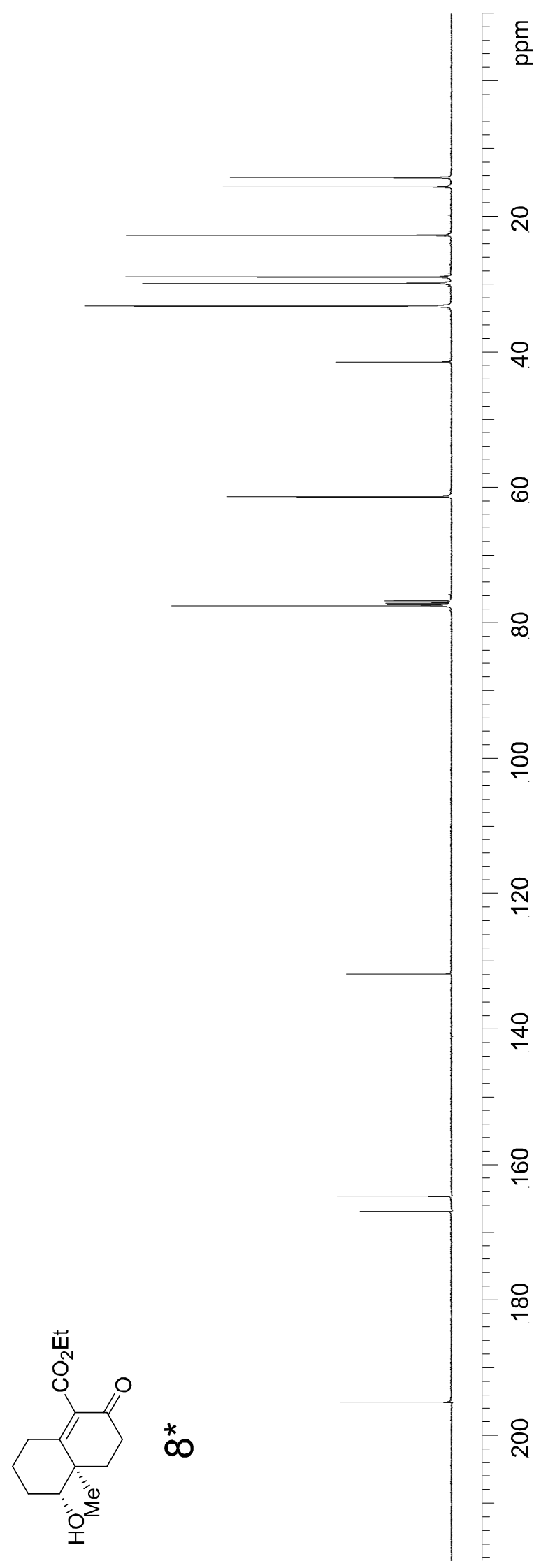




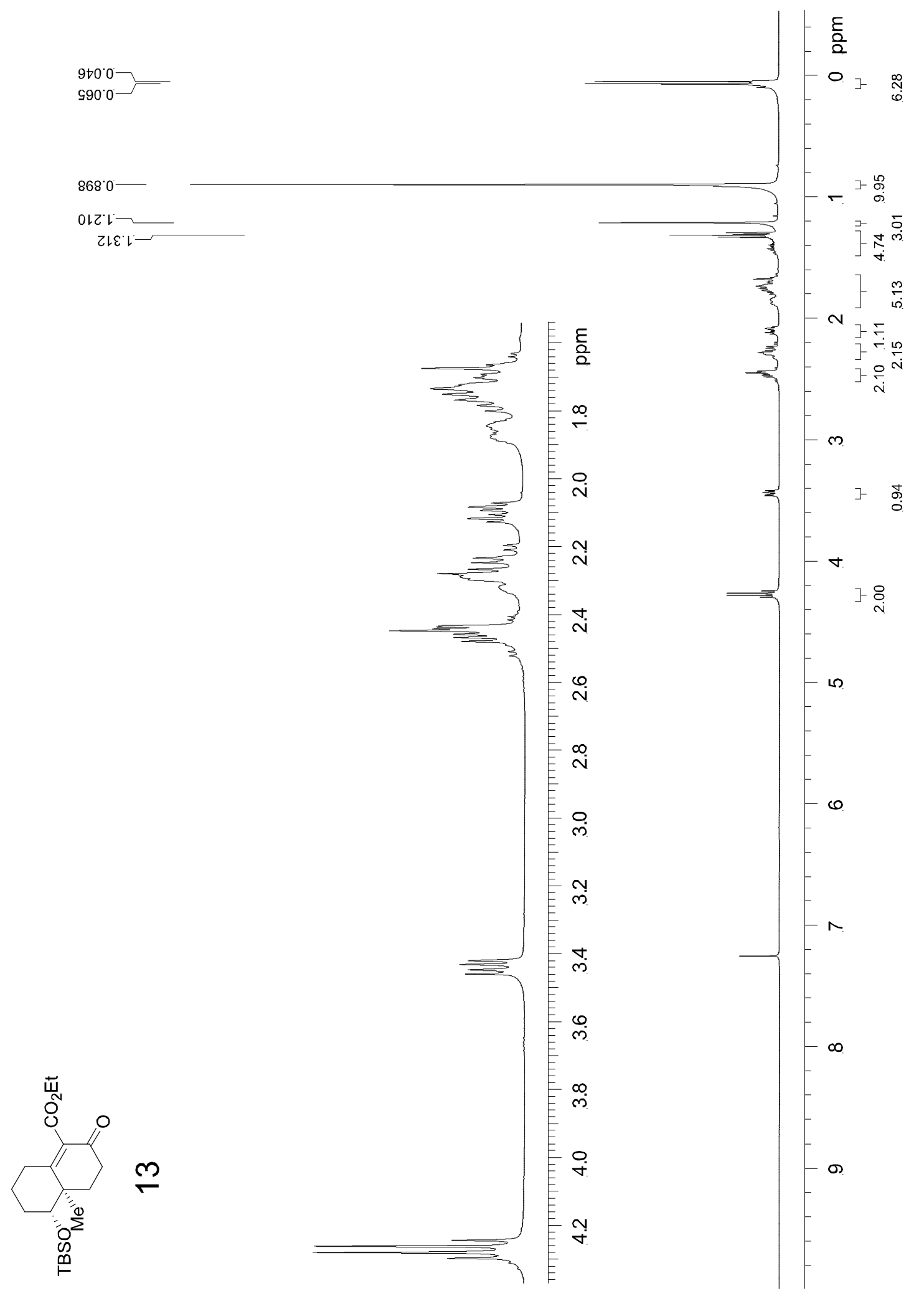




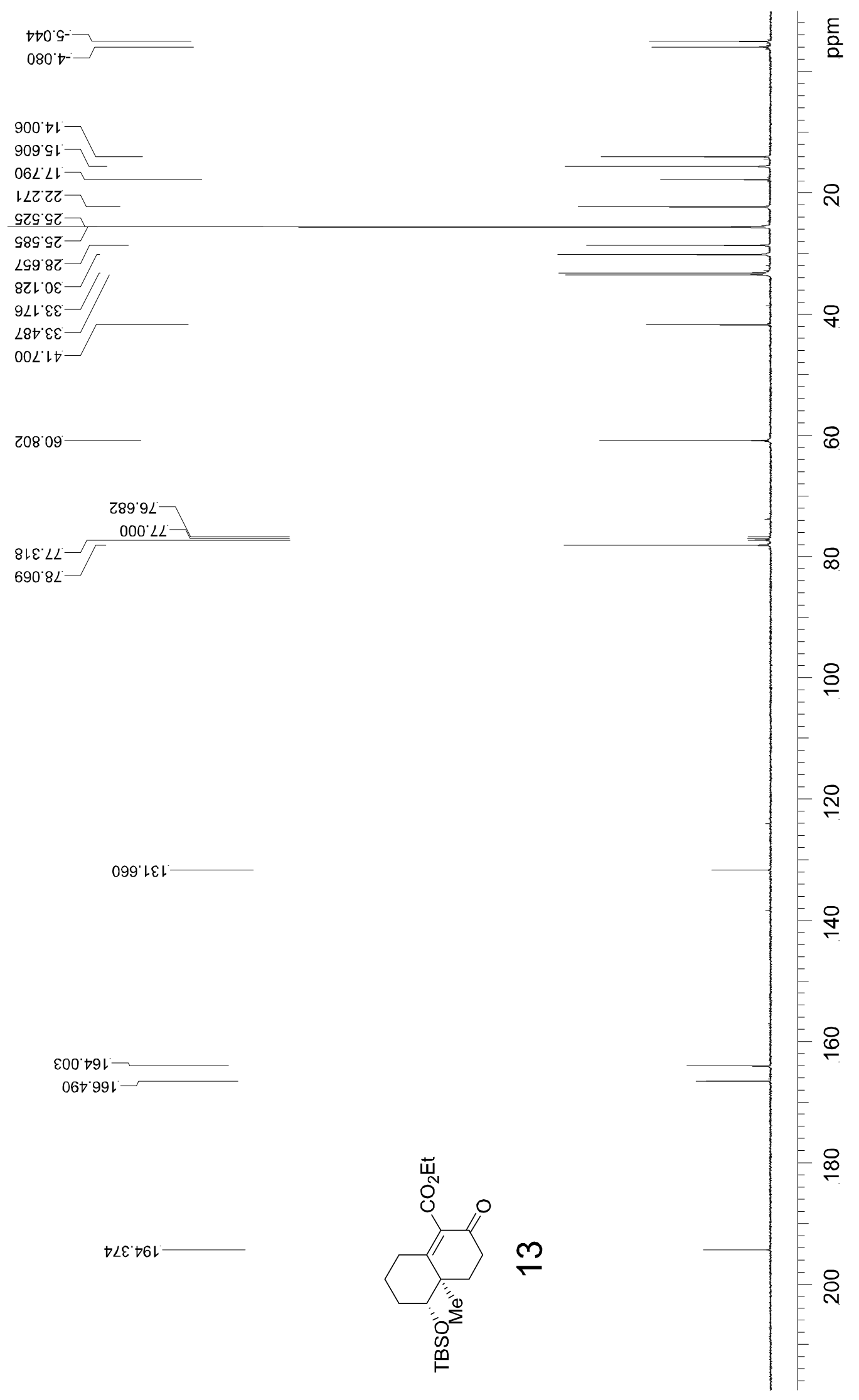




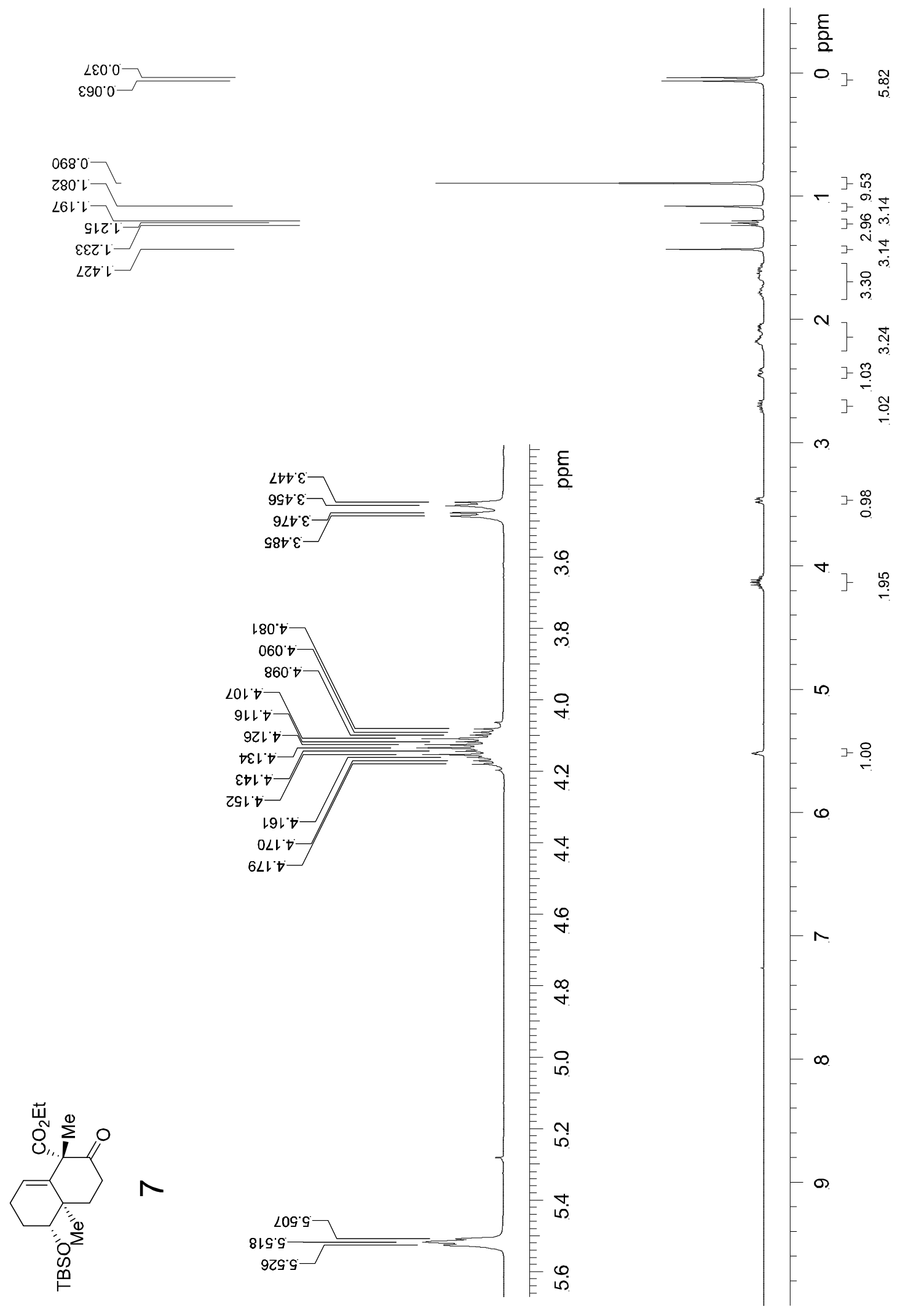




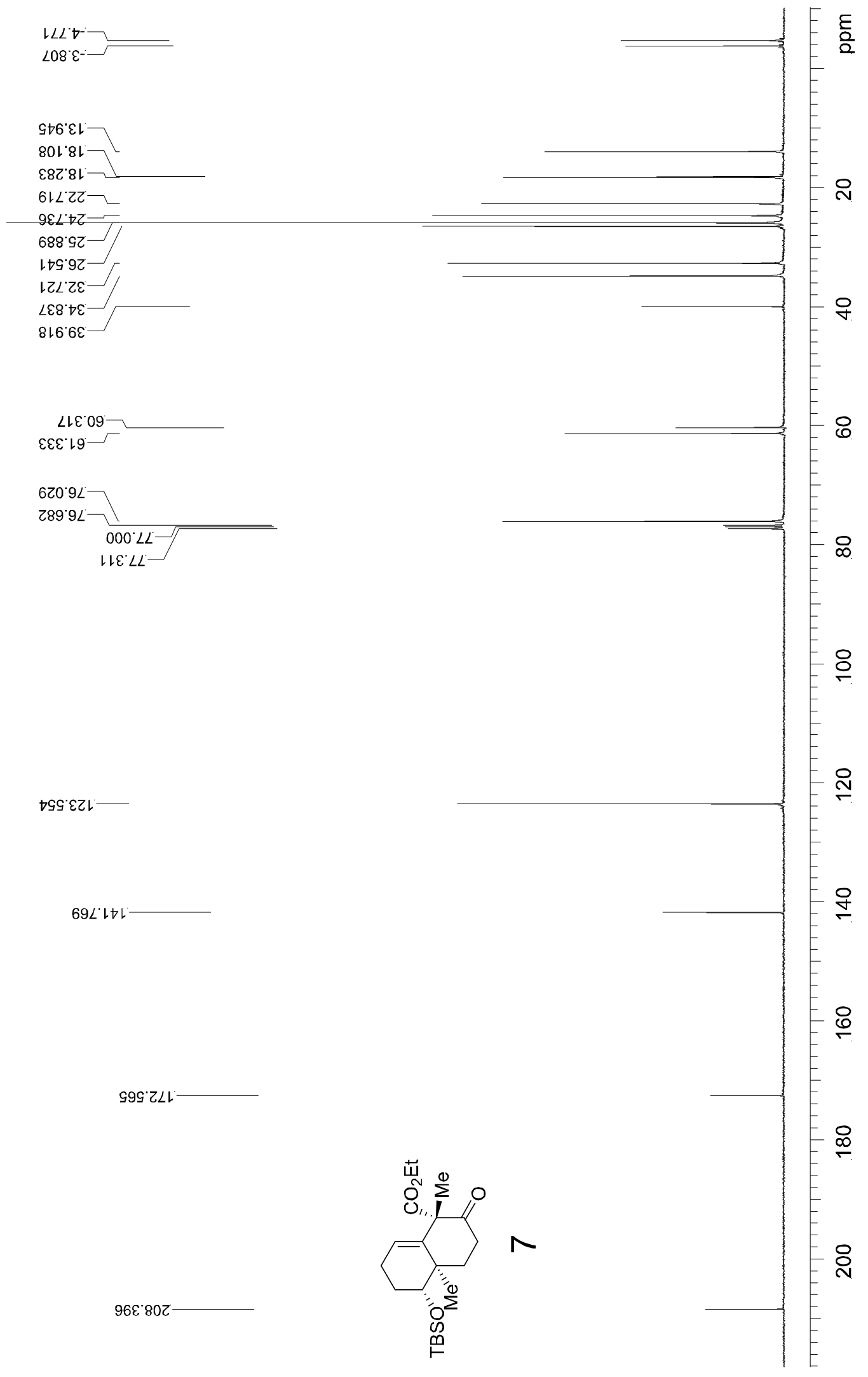




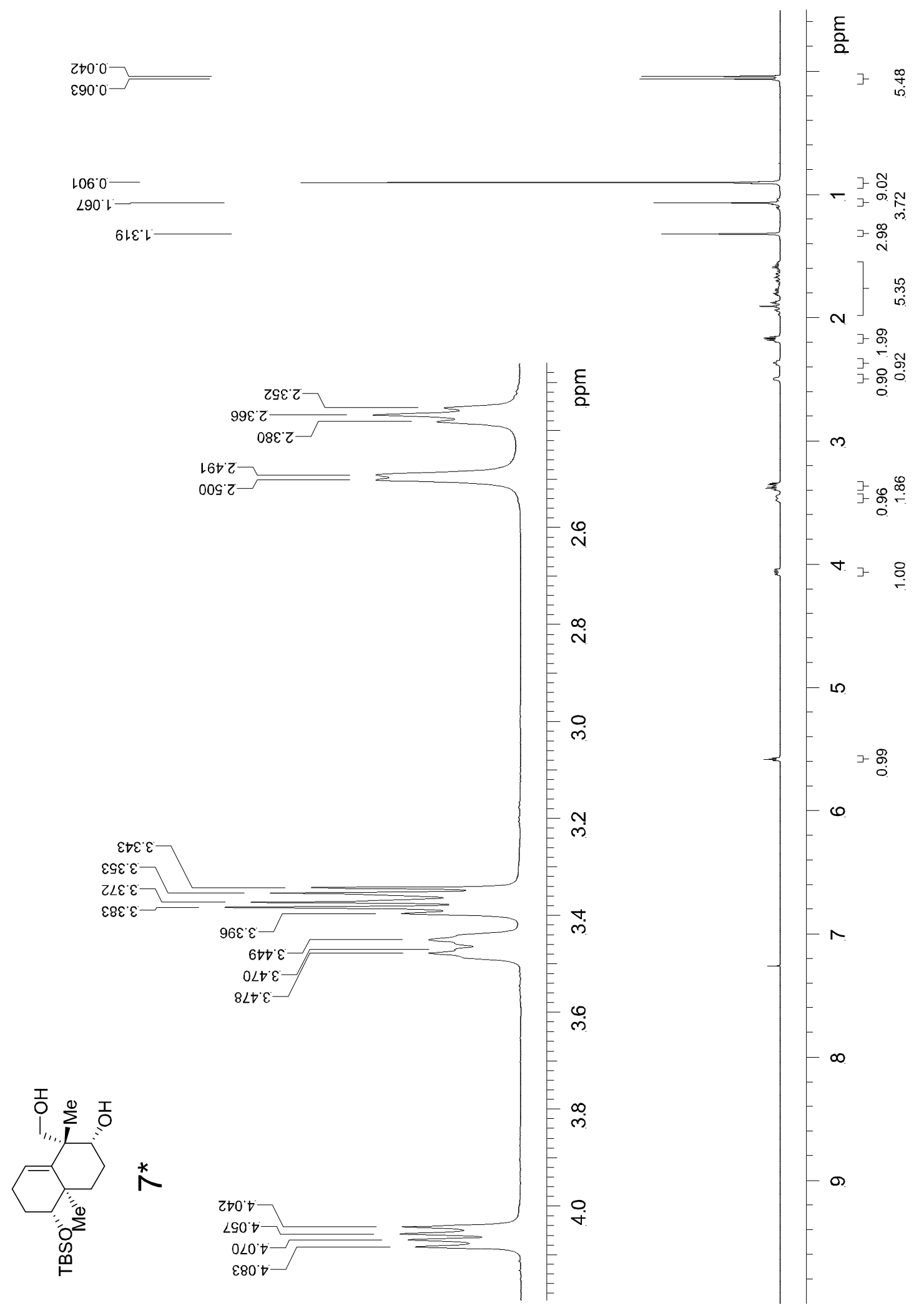




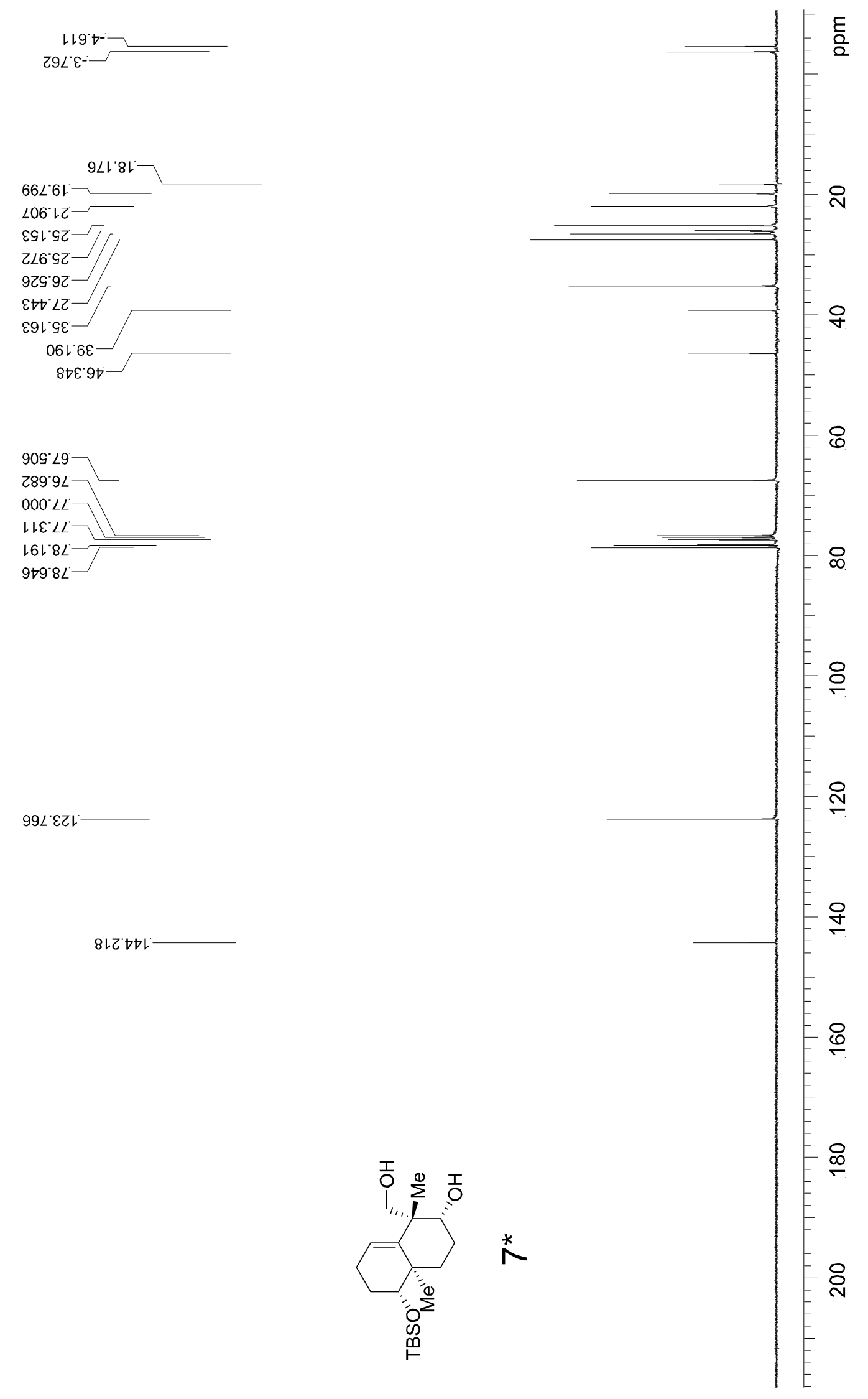




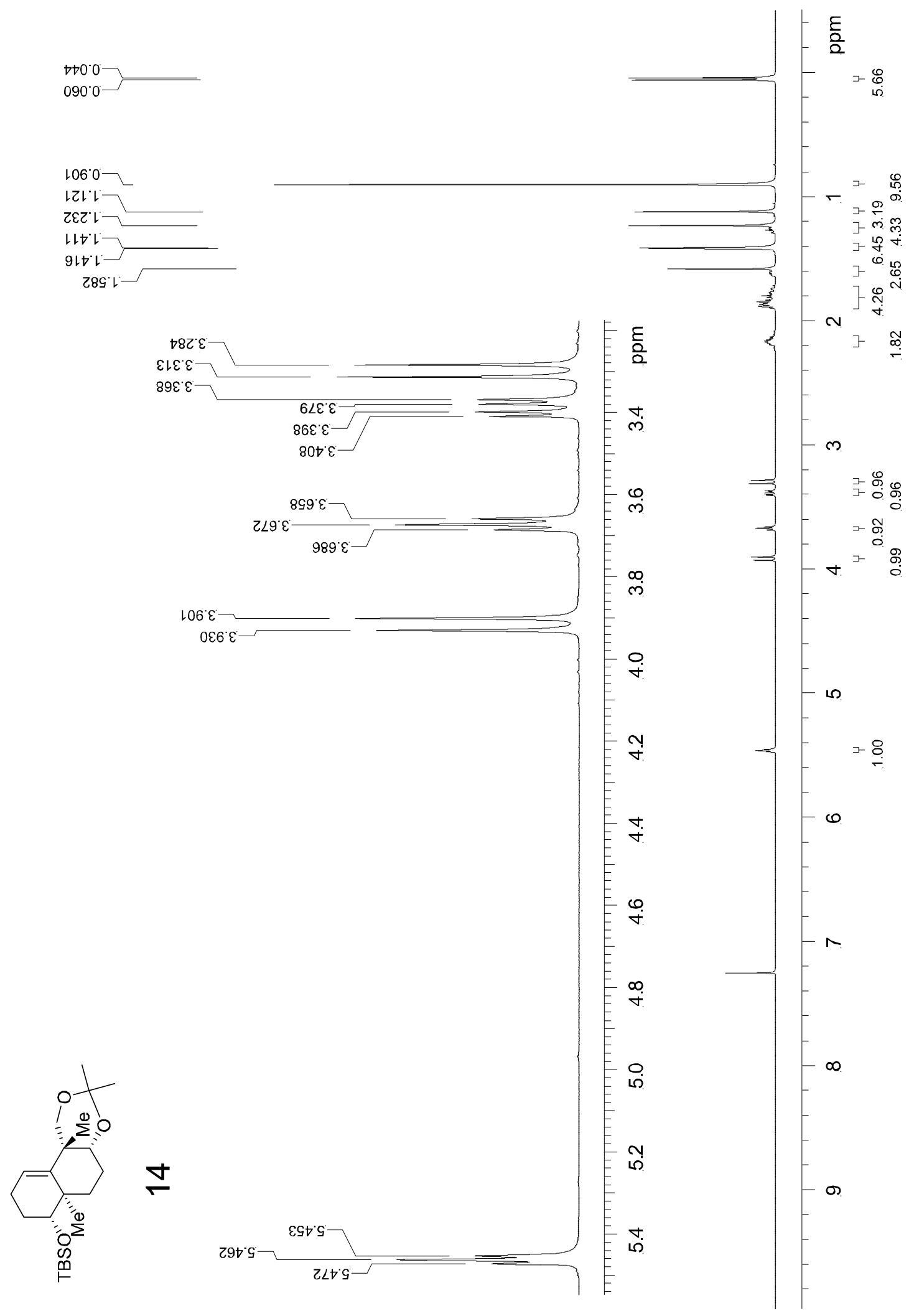




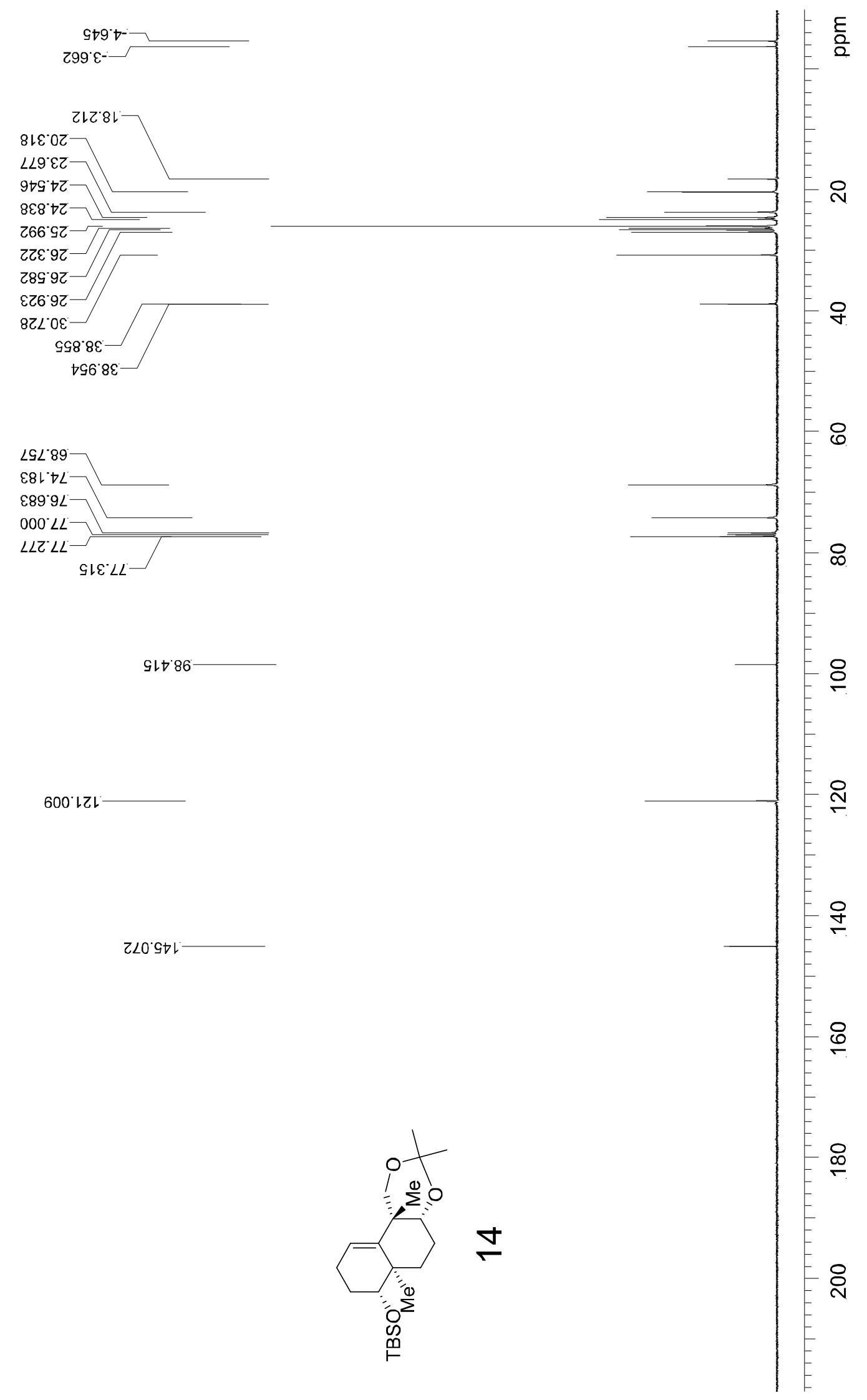




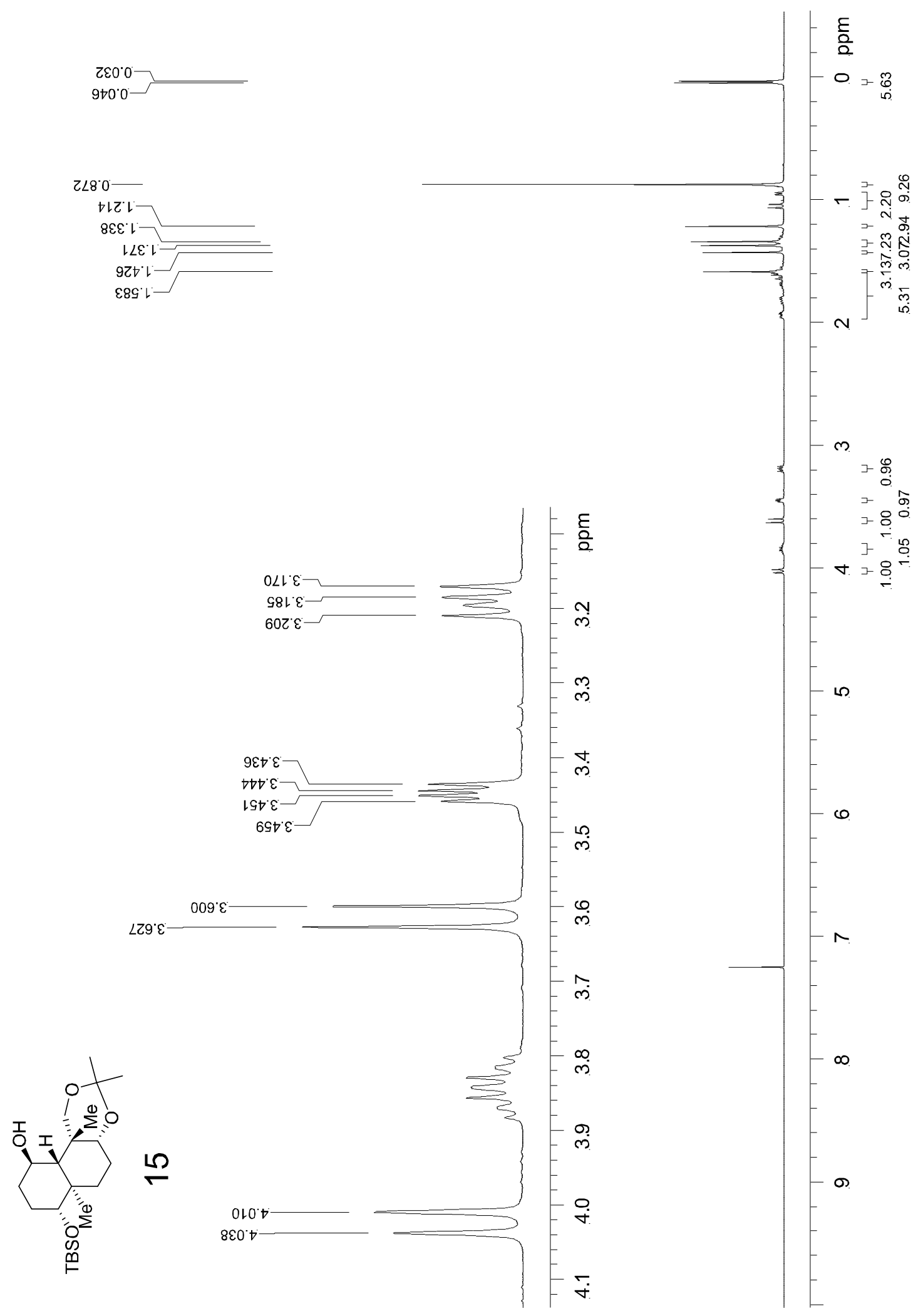




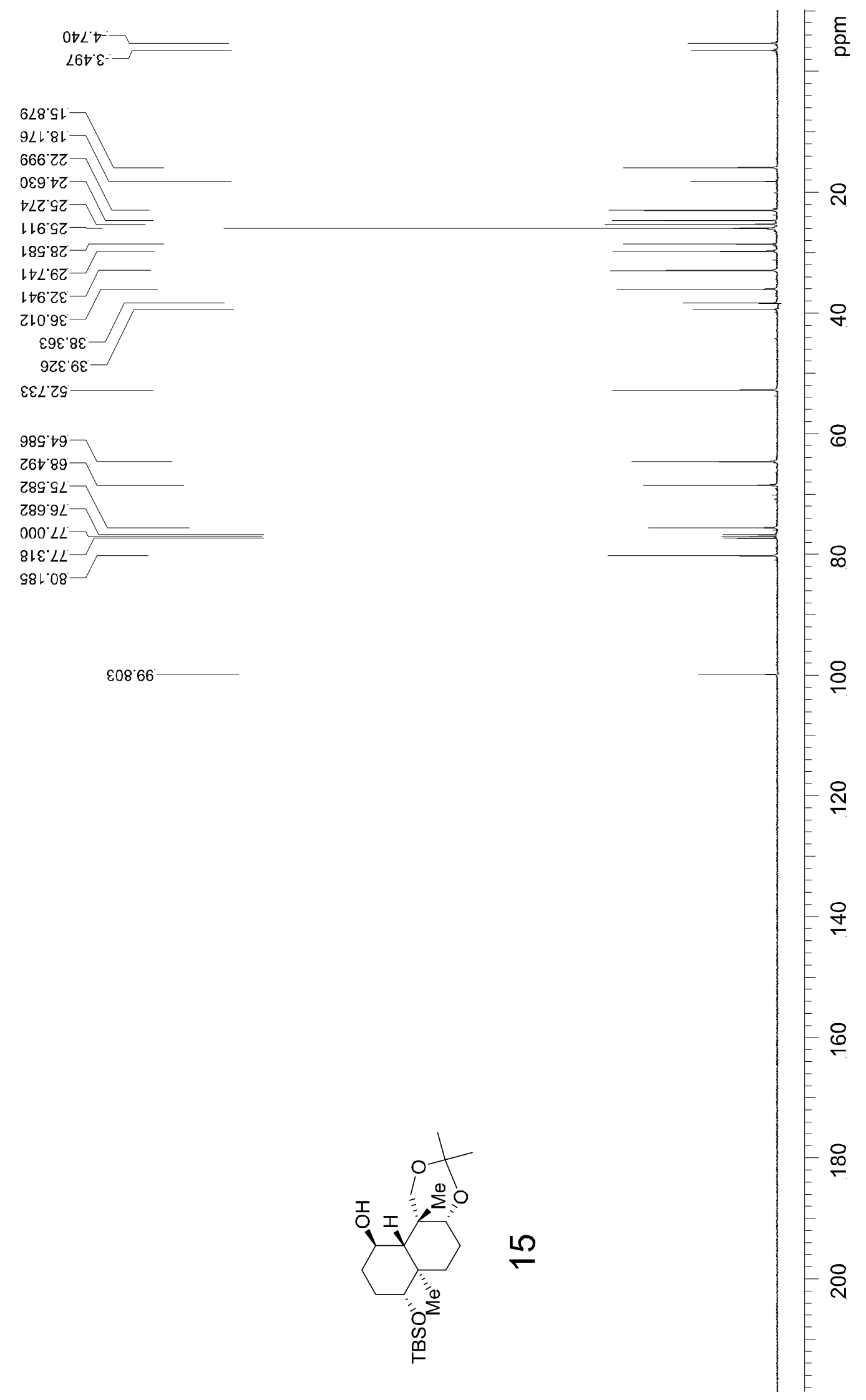




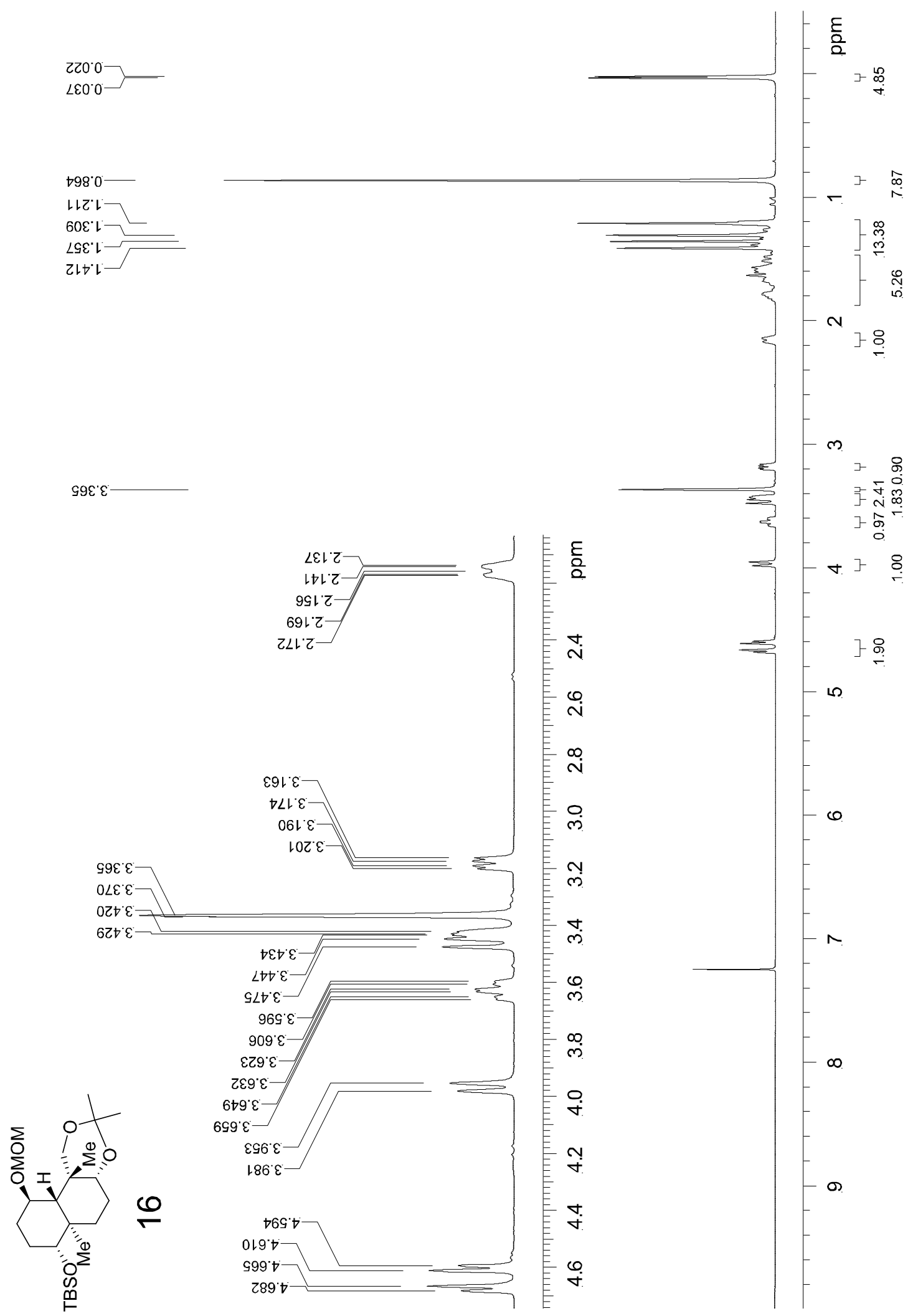




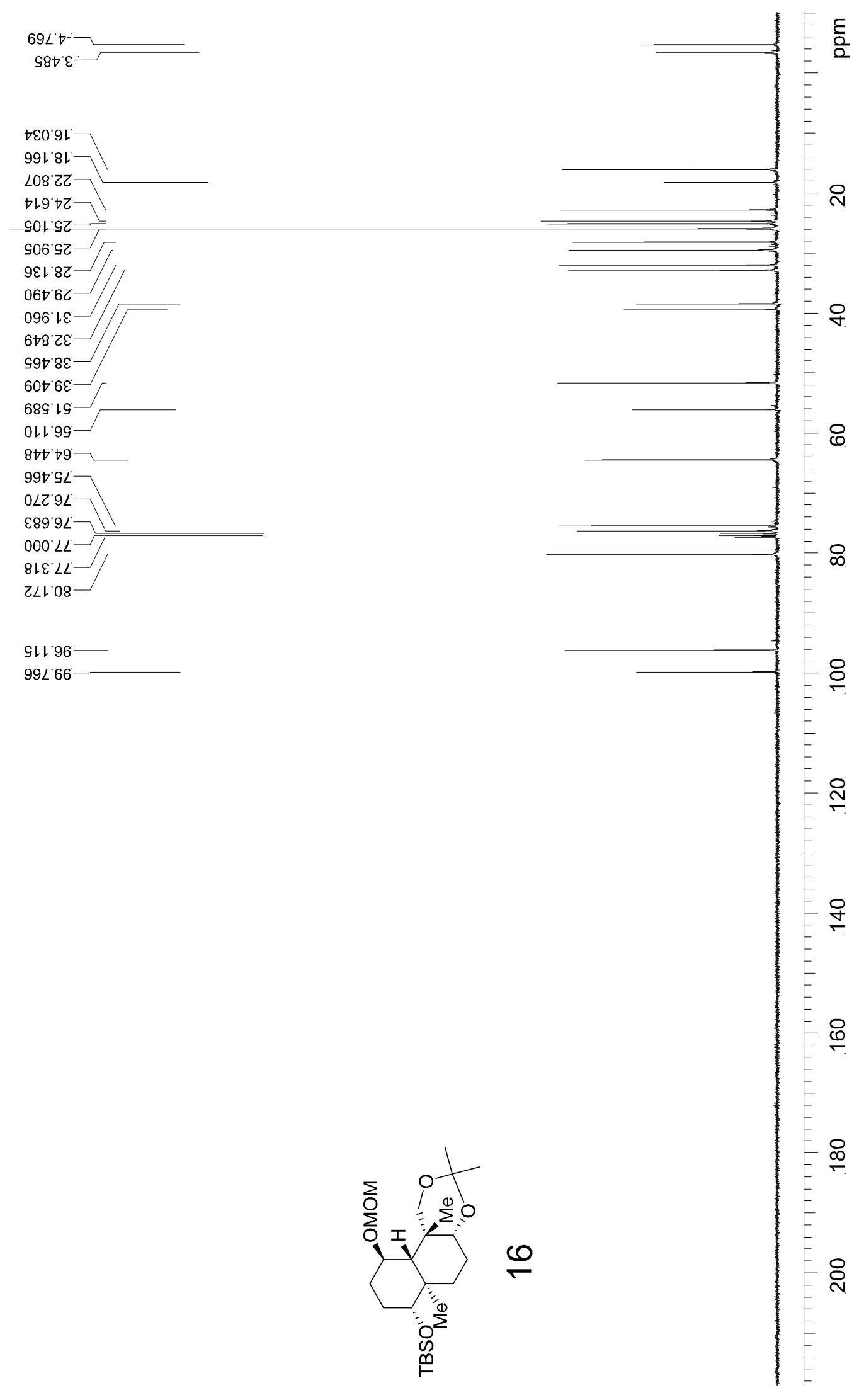




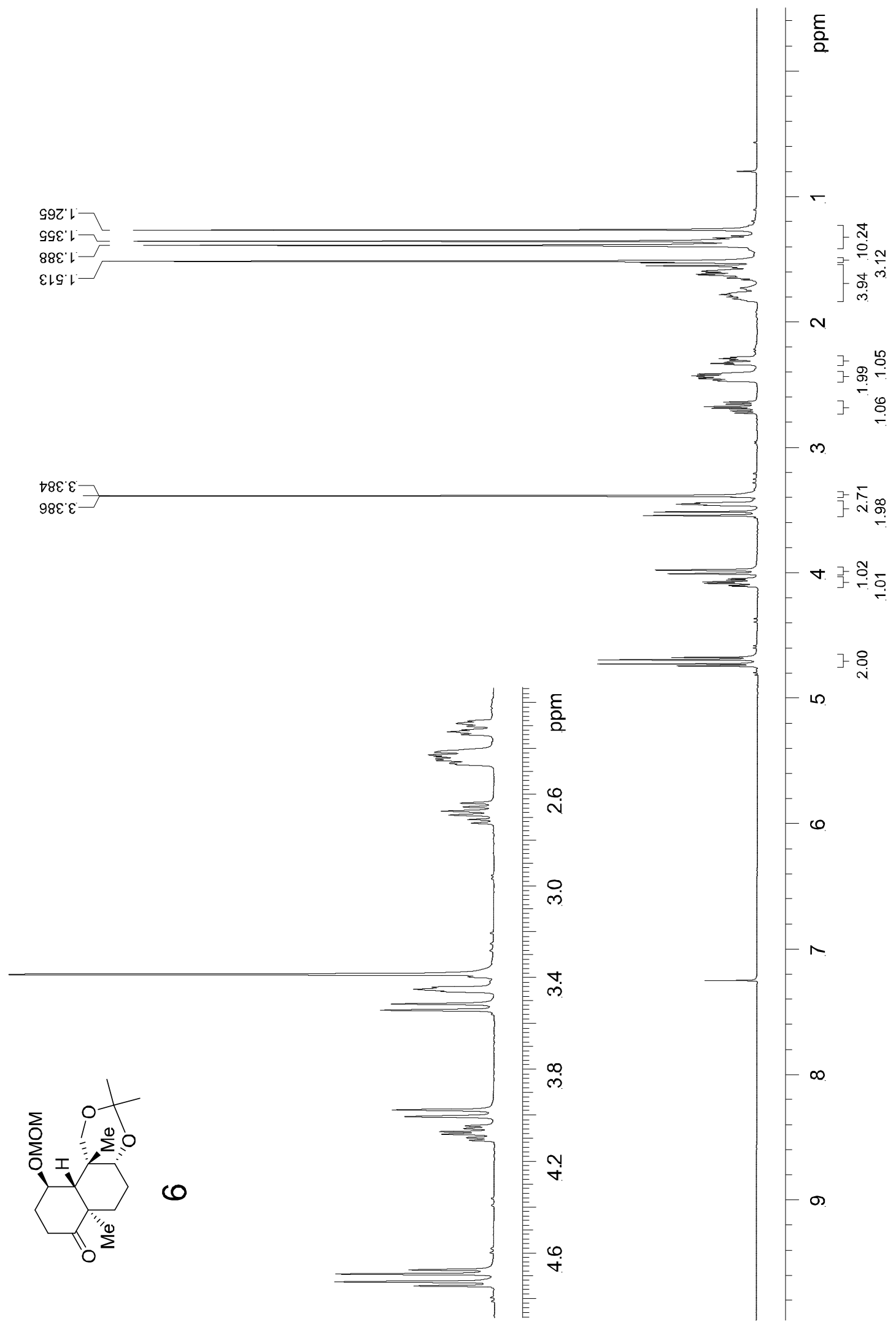



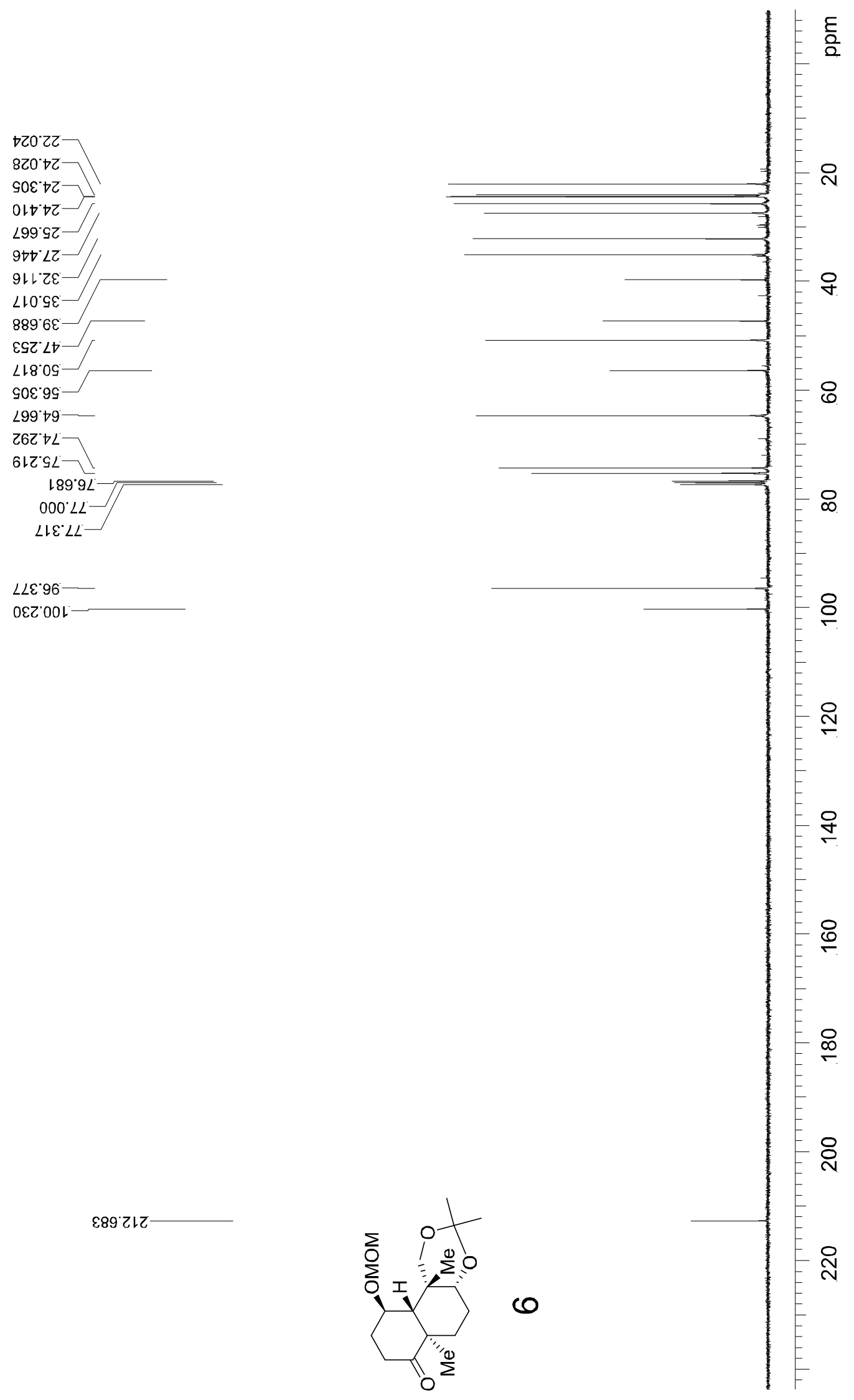


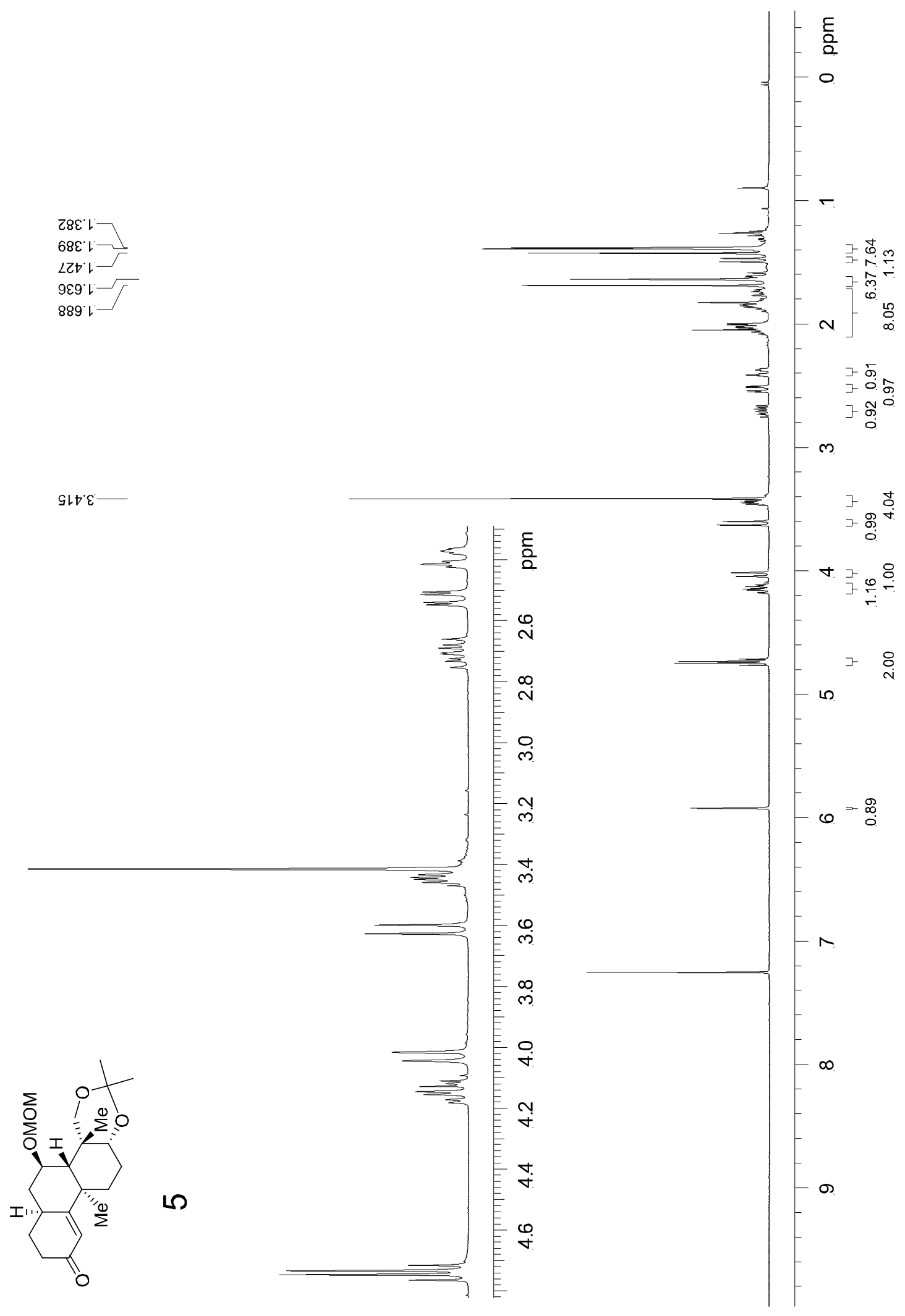



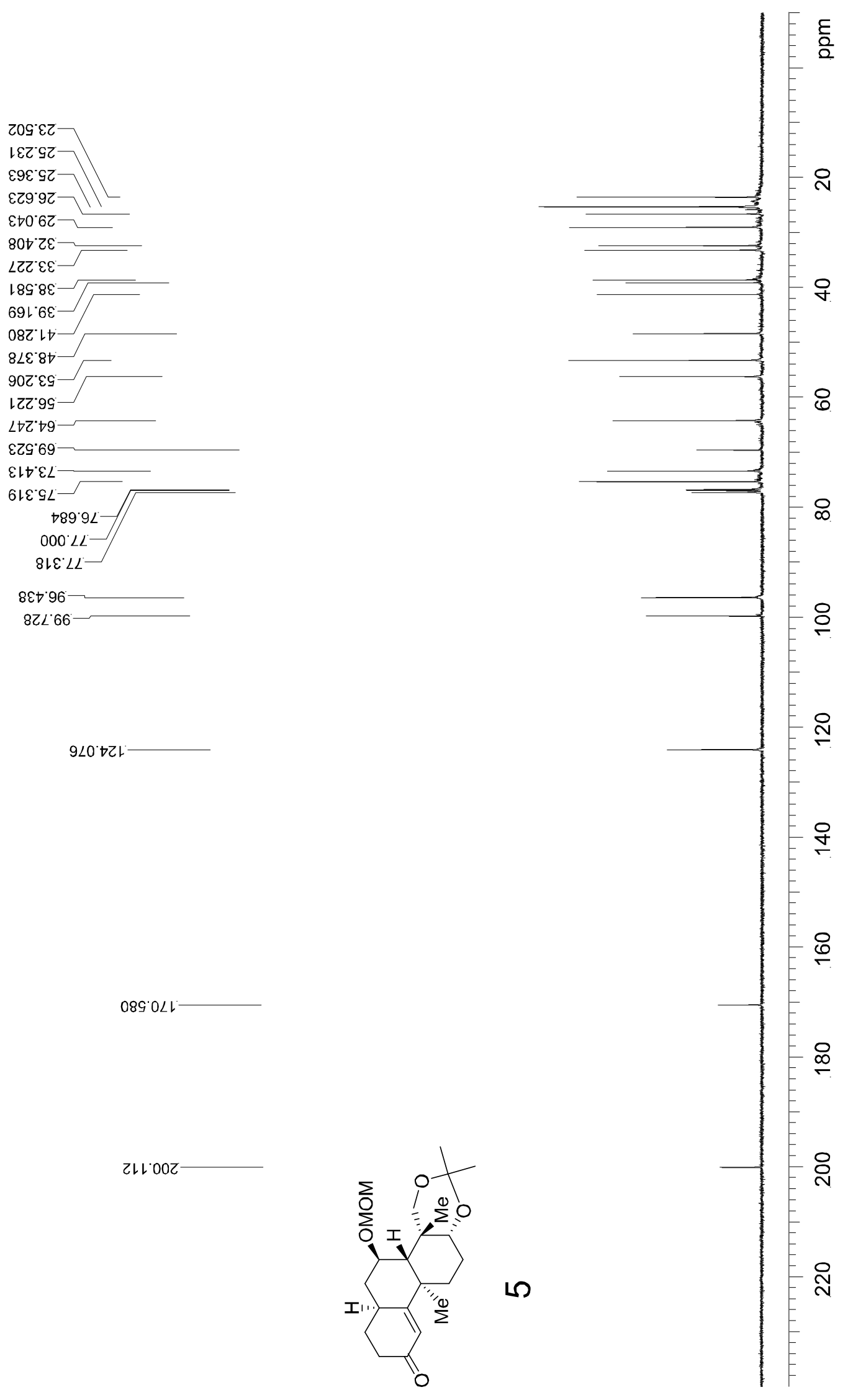


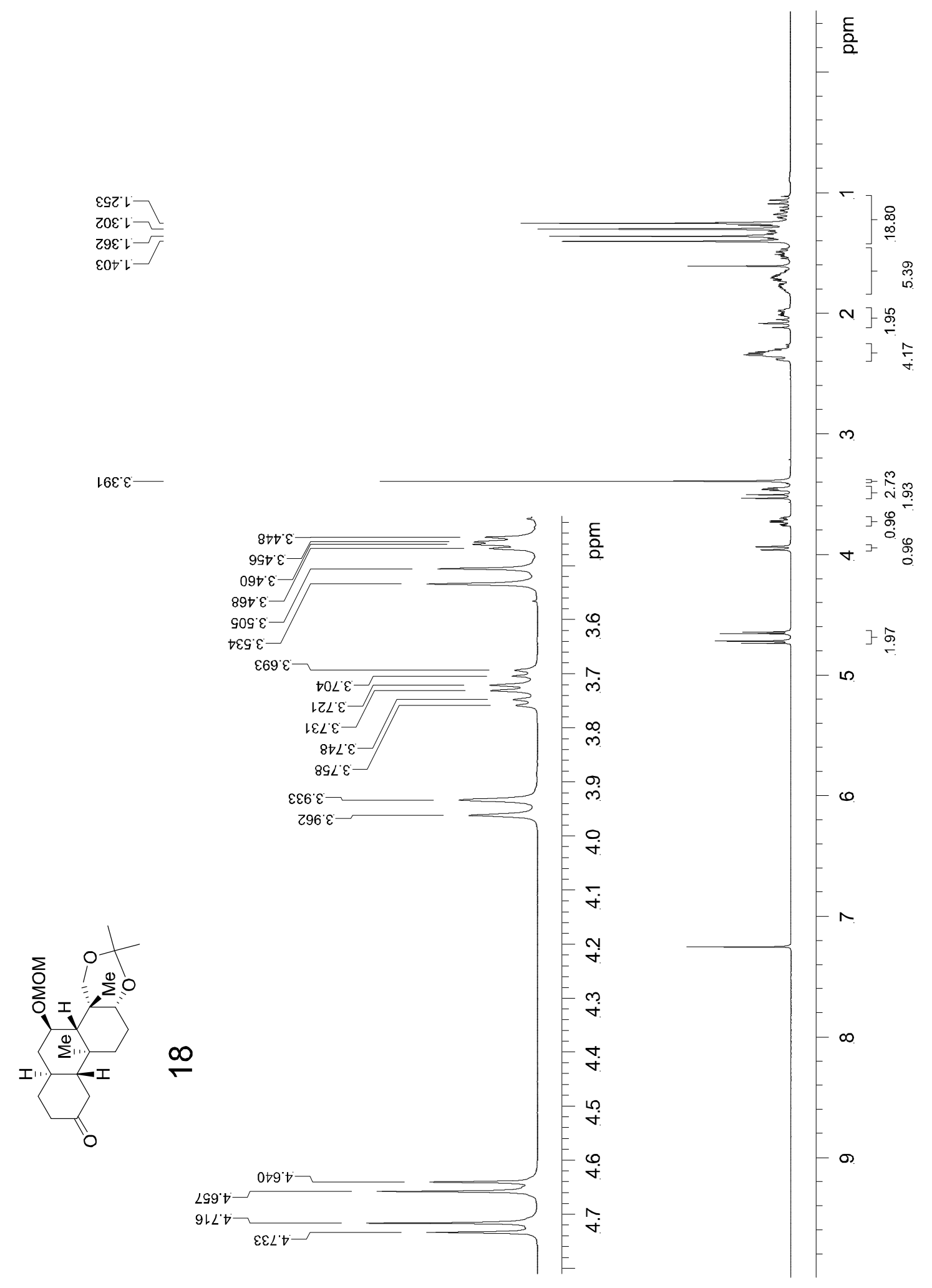



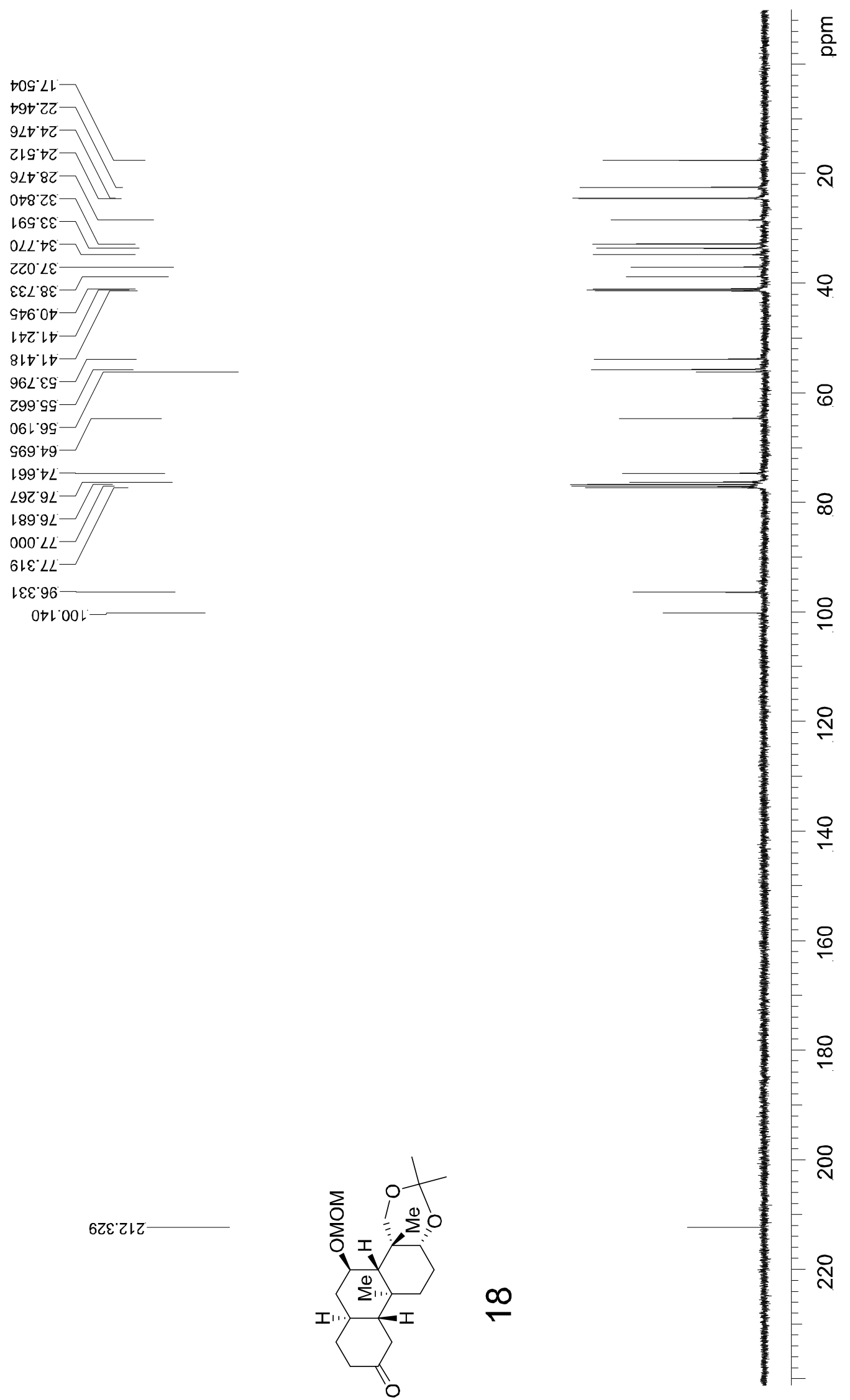


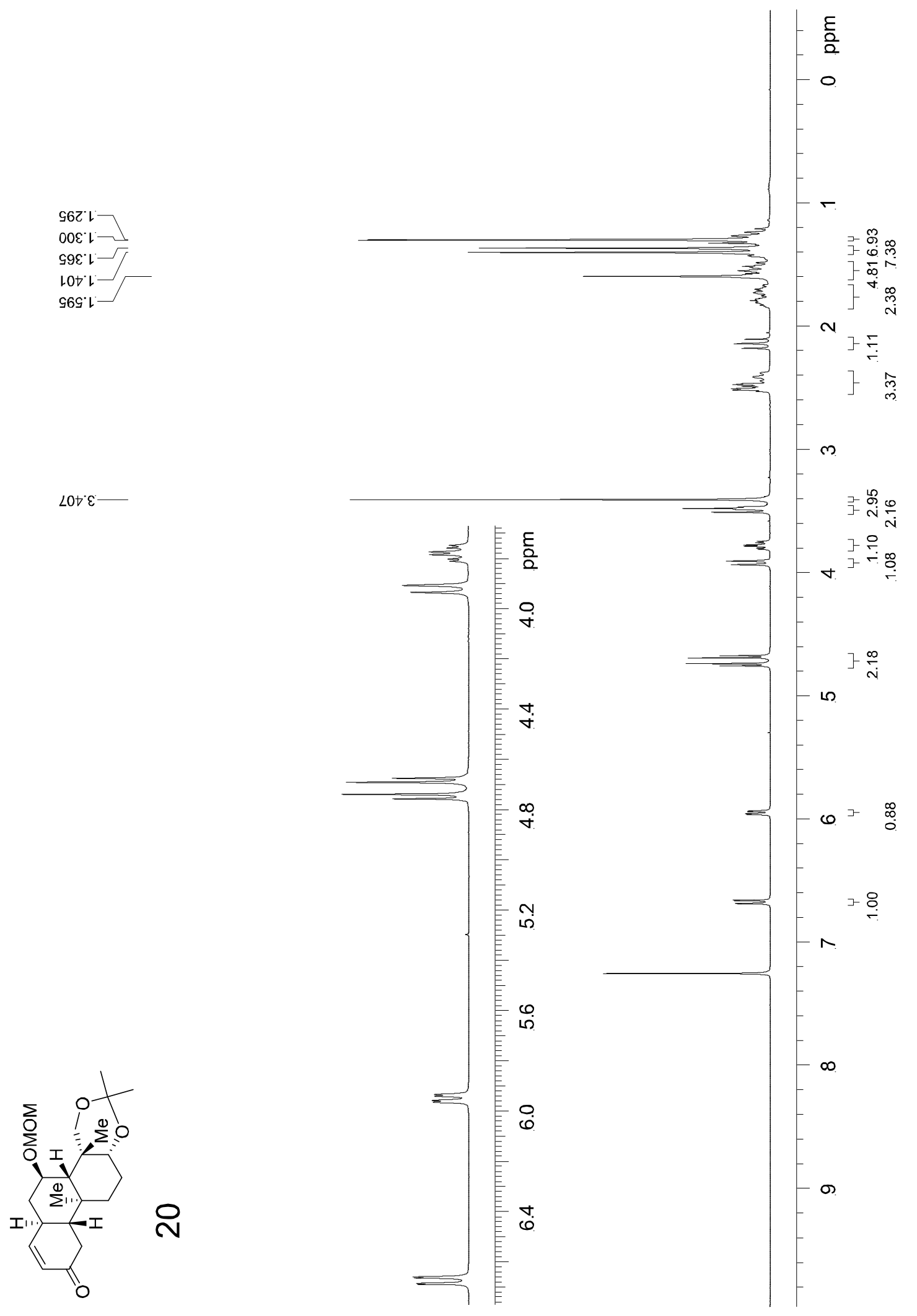



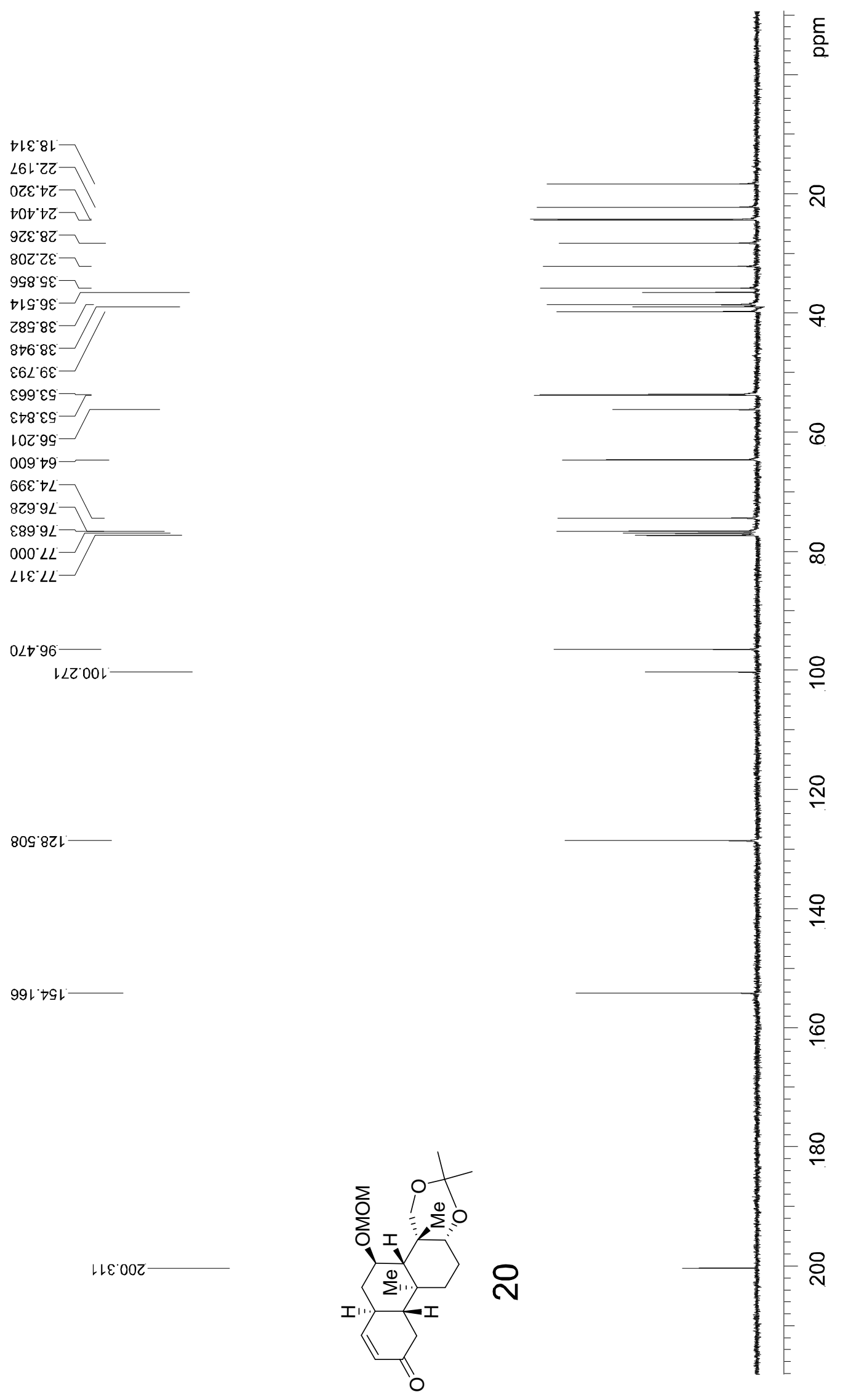

809'8ZL -

99レจงレ

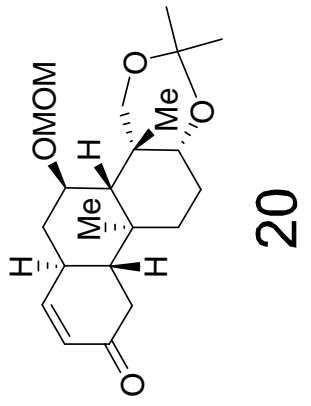




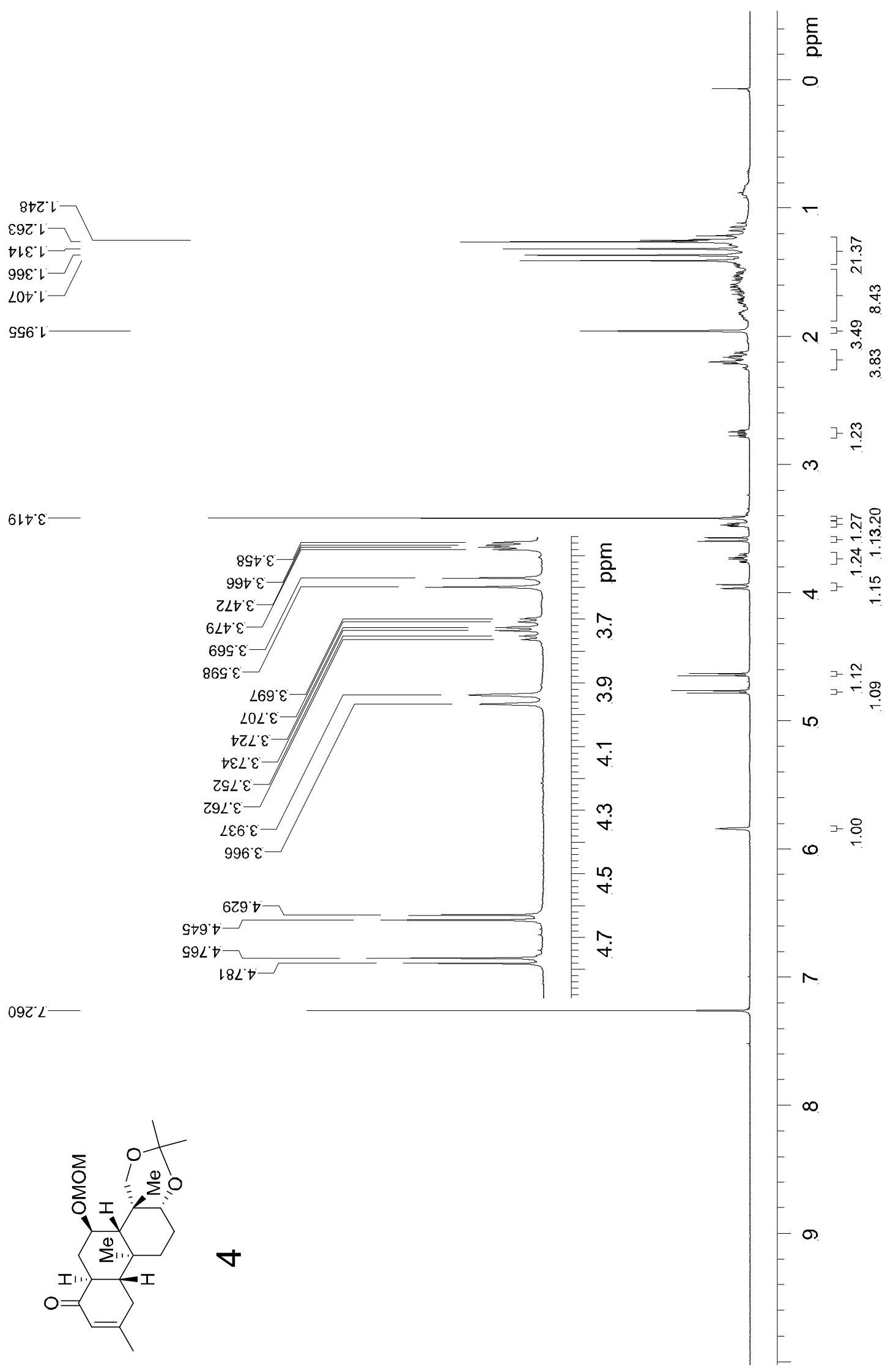




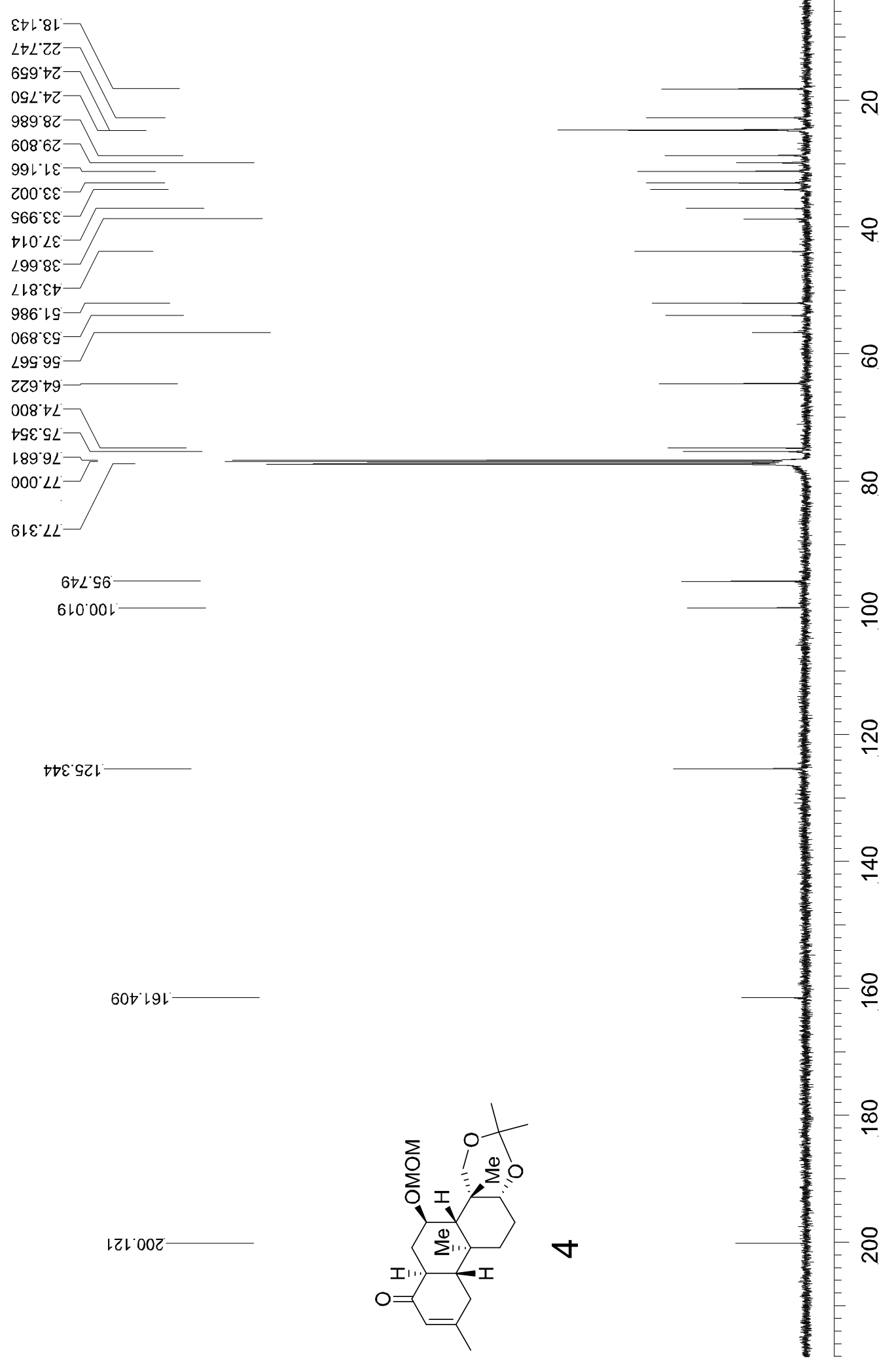

